\title{
THE ENERGY AND INDOOR ENVIRONMENTAL PERFORMANCE OF EGYPTIAN OFFICES: PARAMETER ANALYSIS AND FUTURE POLICY
}

\author{
Aly M. Elharidi ${ }^{1,2, *}$, Paul G. Tuohy ${ }^{1}$, Mohamed A. Teamah ${ }^{2}$ \\ ${ }^{1}$ University of Strathclyde, Energy System Research Unit [ESRU], Glasgow, United Kingdom \\ ${ }^{2}$ Arab Academy for Science, Technology \& Maritime Transport, College of Engineering, \\ Alexandria, Egypt.
}

*Corresponding author. Tel: +201006078383, Fax: +2034273415, E-mail:

aly.elharidi@strath.ac.uk, alyelharidi@aast.edu.

\begin{abstract}
Buildings are a significant contributor to the rapidly increasing electricity demand in Egypt which is straining the existing supply network causing economic and social impacts. There are current initiatives aimed at improved building performance including adoption of international standards. The performance of existing Egyptian buildings is not well understood making the impact of these international standards uncertain. This paper provides insight into performance of current Egyptian office buildings through a multi-building energy survey and a detailed case study. The most common office type in the survey has natural ventilation and local cooling. A process to capture observed performance in a representative model and input parameter set is presented. The model is used to investigate performance impacts of parameters including: location, weather, building envelope, intensity of occupancy, behaviour, and installed systems including the HVAC strategy. HVAC strategy was identified as the most significant factor. Typical Egyptian offices with natural ventilation and local cooling systems under personal control have electricity demand less than $50 \%$ of centrally serviced buildings. System efficiencies (HVAC, lights, equipment) and occupant behaviour (e.g. use of systems, temperatures) were also identified as significant factors, each with potential of around 30\% saving compared to current typical offices. Possible policy measures to promote energy efficient systems and energy conscious behaviour are proposed which together can reduce the energy demand of typical offices by $50 \%$. Trade-offs between energy use and indoor environmental quality (IEQ) are discussed.
\end{abstract}

Abbreviations

\begin{tabular}{|c|c|}
\hline IEQ & Indoor Environmental Quality \\
\hline EPBD & Energy Performance of Buildings Directive \\
\hline EU & European Union \\
\hline UK & United Kingdom \\
\hline ECG 19 & Energy Conservation Guide 19 \\
\hline HVAC & Heating, Ventilation, \& Air Conditioning \\
\hline ECP & Egyptian Commercial Buildings Energy Code \\
\hline ASHRAE & American Society of Heating, Refrigerating and Air-Conditioning Engineers \\
\hline LEED & Leadership in Energy \& Environmental Design \\
\hline EIA & Energy Information Administration \\
\hline USA & United States of America \\
\hline $\mathrm{MBE}$ & Mean Bias Error \\
\hline CV(RMSE) & Coefficient of Variation of Root Mean Square Error \\
\hline PMV & Predicted Mean Vote \\
\hline PPD & Predicted Percentage of Dissatisfaction \\
\hline NV & Natural Ventilation \\
\hline NCS & No Cooling System \\
\hline LCS (or A/C) & Local Cooling Systems under Personal Control (also referred to as 'A/C') \\
\hline MV & Mechanical Ventilation \\
\hline CCS & Central Cooling System \\
\hline HR & Human Resources \\
\hline ETMY & Egyptian Typical Methodology Year \\
\hline IES-VE & Integrated Environmental Solutions - Virtual Environment \\
\hline M.F. & Modulating Factor \\
\hline D.F. & Diversity Factor \\
\hline SEER & Seasonal Energy Efficiency Ratio \\
\hline SEER $_{\text {eff }}$ & Effective Seasonal Energy Efficiency Ratio \\
\hline $\mathrm{CS}$ & Calibrated simulation \\
\hline IC & Influence Co-efficient \\
\hline
\end{tabular}




\section{Introduction}

The rapidly growing world energy use raises concerns over supply difficulties, exhaustion of energy resources, and heavy environmental and societal impacts. The global contribution from buildings towards energy consumption, both residential and commercial, has steadily increased reaching figures between $20 \%$ and $40 \%$ in developed countries. In common with many other nations, Egyptian peak and base load electricity demands have increased greatly, contributing to increasing occurrence of power cuts and blackouts. One key driver for demand growth has been increased urban development concentrated in the Nile Delta [1]. Urban development resulted in particular problems with cooling demands in summer months, associated also with a shift from traditional vernacular designs [2]. New buildings were not required to meet any energy performance standards until 2005 with the introduction of the new code, Egyptian Commercial Buildings Energy Code ECP 306-2005[3], part of the Egyptian Government integrated energy strategy, aiming to reduce energy demand, and to provide the secure, reliable and affordable energy services in support of economic stability and development [4]. The new codes are largely based on international standards (ASHRAE, ECP) [5],[6]. In parallel there is increasing adoption of voluntary sustainability rating systems such as LEED [7] and a new Egyptian sustainability rating system called Green Pyramid [8].

Potential concerns with the adoption of these new standards are: (i) that the current energy performance of Egyptian buildings is not well known so the change in performance from adoption of these new design standards is therefore uncertain; (ii) that the appropriateness of these new build design standards to the Egyptian context (weather, customs) has not been fully explored; and (iii) that the new standards are not generally being applied to existing buildings which is an essential part of reducing overall demand. To be able to address these concerns, and appropriately inform future strategy, it would appear to be essential to first characterise the energy and indoor environmental performance of the existing building stock and then to encapsulate this performance in a representative model, then to use that model to inform an appropriate future strategy. Many building types make up the stock, in this work, the main focus is on typical Egyptian offices however the methods developed are intended to be equally applicable to other building sectors and contexts.

Various methods have historically been used to represent energy and environmental performance of buildings ranging from statistical black box to detailed physical models Clarke (2001) [9], Reedy \& Andersen (2002) [10], Zhao \& Magoules (2012) [11], Attia (2012) [12]. Modelling of building stocks has variously been approached through bottom up statistical and/or engineering methods, and also top down statistical methods [13], [14].

30 Statistical methods rely on data being available preferably for multiple individual buildings and disaggregated by energy use and IEQ parameter, and energy use at the stock level. Availability of such data is an issue for the Egyptian office stock. Mauro et al (2015) [15] and Ascione et al (2016) [16] have formulated a bottom up simulation based approach where building categories are established based on geometrical, thermo-physical and 'other' parameter sets where 'other' covers such parameters as setpoints, people loads, and temperatures which 35 has been used to assess cost optimum building upgrades to inform policy in the context of Italy, uncertainty in model input parameters has been imposed and considered in the outputs.

Dynamic simulation models are increasingly frequently used, these models represent physical behaviour at various levels of detail [17], [18]. Dynamic simulation is used to underpin performance standards such as the EU Energy Performance of Buildings Directive (EPBD) [19] and the UK Building regulations [20] etc. and has been widely used to inform future building strategies [17]. There are many dynamic simulation tools available many meeting internationally agreed standards [21], [22]. In this work the IES-VE 2014 was selected, it has worldwide accreditation and supports numerous regulatory and voluntary standards [23].

For any model calibration is a key requirement for results to be reliable [24]. Calibration processes for building performance models have been a research focus in recent years [18],[20],[25]. ASHRAE Guideline 14-2002 [26] provides standard methods and uses Mean Bias Error (MBE) (\%), and Coefficient of Variation of Root Mean Square Error CV(RMSE) (\%). In this work a calibration approach based on the ASHRAE Guideline, the work of Coakely (2011) [27] and Reftrey (2011) [28] is used where a best guess model is constructed based on available data, uncertain parameters are screened for relative influence, then values adjusted sequentially to minimise errors [29].

50 Measured building performance data is required to inform modelling and calibration processes. There are many building performance datasets available worldwide e.g.UK Probe and Energy Consumption studies [30],[31], US Building Performance Studies [32] These are used to inform model calibration and regulatory compliance tools (e.g. EN15252, UK NCM [33]). It is common practice to categorise office buildings by type e.g. the UK Energy Conservation Guide 19 (ECG 19) [31] categorises offices into 4 types based on form, function, and service strategy, and gives typical and best practice values for different energy use categories. Crawley gives the electricity usage for US offices as ranging between 226 and $317 \mathrm{kWh} / \mathrm{m}^{2}$ p.a.[17]. There is limited data for the 
Egyptian context. Abdelhafez [34] has gathered monthly electric bill data for a single head office in Cairo over 2 years and gives $202 \mathrm{kWh} / \mathrm{m} 2$ p.a. as the total annual energy use (all electric) and $162 \mathrm{kWh} / \mathrm{m}^{2}$ p.a. for the office equipment, lighting and HVAC. Ezzeldin (2011) [35] modelled cooling strategies for a single prototypical office building in Cairo, Egypt, and gives mixed mode energy use ranging from 70 to $100 \mathrm{kWh} / \mathrm{m}^{2}$ p.a. and central HVAC averaging $170 \mathrm{kWh} / \mathrm{m}^{2}$ p.a. depending on internal gains scenario. The model was based however on many variables like the lighting density, equipment density estimated using standards and codes rather than measured. In general, there is a shortage of measured data for the Egyptian office context.

Measured building performance data is also of key importance in addressing the potential 'performance gap' between intended and actual building performance which has been internationally recognised [36],[37],[38],[39]. It would appear to be important in the Egyptian context that performance feedback is integrated in future policy to avoid the performance gaps seen elsewhere.

The use of building simulation tools in Egypt was historically low [40]. The situation is starting to change. There are several recent examples of such tools being used for residential buildings [41] [42] [43] [44]. In the Egyptian office sector ElDabosy and AbdElrahman (2013) [45] investigated façade designs for a single office. ElMohimen et al. (2005) [46] applied building simulation to study daylighting in a specific Egyptian office building. Ezzeldin (2011) [35] examined mixed-mode cooling strategies for an existing modern typical office in Cairo. Saleem et al. (2016) [47] examined indoor comfort conditions and energy consumption. Sheta \& Sharples (2010) [48] used measured data to apply a calibration process for inside room temperature. Hanna (2013) [49] used simulation to investigate facades. While these studies provide insights there remain gaps to be able to characterise the performance of existing office buildings in models to support more general policy development.

Non-adaptive and alternative adaptive criteria for thermal comfort are both encapsulated in international standards [50], [26]. The extent to which these apply in the existing Egyptian Office context remains to be explored. Givoni [51] investigated the boundaries of the thermal comfort zone in relation to clothing levels and air movement, noting large shifts in summer comfort temperature. In Japan in 2005, the successful Cool Biz campaign [52] was launched to exploit this effect to reduce energy demand for air-conditioning during summer.

In Egypt, recently multimedia initiatives were launched in the residential sector to raise awareness of users of energy use in buildings. These focused on lighting systems, urging the use of natural light during the day, turning off lighting in unoccupied spaces, and promoted energy-saving bulbs, efficient air conditioners, and setting cooling temperatures to $25^{\circ} \mathrm{C}$. Similar public initiatives have not yet been launched in the non-residential sector.

\subsection{Research Gap}

To develop well founded policy for the office sector in Egypt is necessary: (i) to understand the current energy and IEQ performance of existing Egyptian offices, then (ii) to embed this knowledge within a valid modelling framework, and (iii) to make use of this framework to investigate future scenarios, and (iv) provide outputs that can usefully inform future strategy and policy for the sector. Currently there are gaps in each of these areas with a lack of understanding of current performance, no well-established modelling framework that captures existing performance, and limited parametric studies to usefully inform future policy scenarios.

\subsection{Aims and Methodology}

The specific aims of the research presented here were:

- To identify the energy and IEQ performance associated with current Egyptian office buildings.

- To show how this can be embedded in a valid modelling framework.

- To use this modelling framework to investigate the relative and combinatorial impact of apposite parameters, and to present this information in a useful form.

- To propose possible future measures for Egyptian office buildings that will minimise energy use.

- To illustrate a process can be usefully extended to other sectors and contexts.

To achieve this aims the following methodology was used:

- Evidence was gathered for current Egyptian office energy and IEQ performance from: literature, a building energy survey, and a detailed investigation for a case study office. Thermal comfort standard appropriate to the Egyptian context was investigated.

- The gathered data was used to create a modelling framework consisting of a typical model, and worst case parameter sets describing likely variations in input parameters.

- The modelling framework was then used to demonstrate relative and combinatorial effects of various input parameters grouped into appropriate categories and modulated in realistic ranges. 
- The modelling framework was used to investigate the impacts of various parameters and identify those that can be useful to mitigate the growth of energy demand in the office sector and be encouraged by policy.

\section{Existing Egyptian offices: Energy performance, IEQ, and Behaviors.}

5 Evidence was first gathered to establish energy performance of Egyptian offices through a 59 building energy survey and supplementary data from literature. Offices were categorised by their services strategy. A more detailed investigation into energy, IEQ comfort and occupant behaviour was then carried out for a case study office with the most commonly observed service strategy (natural ventilation with local cooling systems).

The building survey, building model, and model calibration are described here in a summarised form; more details (e.g. measurement instruments, model parameter calibrations) are available in a previous publication [53].

\subsection{General Survey of Energy use in Egyptian Offices.}

The simple field survey was conducted for 59 offices in Alexandria, North Coastal Egypt. Data recorded included: office total internal floor area, office business activity, building type, building services type, and electricity bill data for 12 continuous months during 2013-2014. The surveyed offices included lawyers, accountants, travel agents, sales, health administration, insurance, consultants, bank administration, human resources, and Government. Surveyed offices were within both mixed office / residential buildings and in single function multi-floor offices.

The surveyed offices were categorised into 4 types by service strategy as shown in Table 1 and the type of buildings illustrated in Figure 1. Annual energy use is summarised by service strategy in Table 2 which also gives a comparison with the UK ECG19 data for electricity use (the ECG19 energy for space heating has been excluded, as not relevant to the Egypt context). The survey only included 2 buildings with central HVAC. To supplement the survey data the published monthly electrical energy data of Abdelhafez [34] and Ezzeldin [35] for this type of Egyptian office is also presented in Table 2. Abdelhafez gives $202 \mathrm{kWh} / \mathrm{m}^{2}$ p.a. as total energy use, and $162 \mathrm{kWh} / \mathrm{m}^{2}$ p.a. for HVAC, lights and equipment over 2 years of monitoring, the difference is possibly infrastructure such as lifts or external security lights. Ezzeldin [35] reported total energy use within the range of 118 to 237 with an average of $170 \mathrm{kWh} / \mathrm{m}^{2}$ p.a. depending on specific pattern of use. These values are consistent with those measured in the survey.

Monthly energy use by service strategy is shown in Figure 2, Here and throughout the paper 'Local Cooling System (LCS)' is used as an abbreviation of 'Local cooling under personal control through individual unitary or split systems' also colloquially referred to as "A/C".

The survey data shows that the naturally ventilated offices without cooling have the lowest energy use, those with cooling systems have higher consumption particularly in summer months, offices with mechanical ventilation have higher energy use than those with natural ventilation, and those with centralised cooling or centralised HVAC have the highest consumption. The results show the same trend as in the UK Energy Conservation Guide 19 (ECG 19) [31] as shown Table 2, where more highly serviced buildings consume higher levels of electrical energy, however it appears that in general the total electrical energy use is lower for the Egyptian offices in the survey than the UK or US benchmarks.

While the monthly bill data of the survey provides some useful insight, a more detailed performance survey is required to provide deeper understanding and inform the creation of a representative simulation model. 
Table 1. Egyptian office survey overview

\begin{tabular}{c|c|c|c|c} 
Office Type & No. of survey offices & Ventilation System & Cooling System & Description \\
\hline Type 1 & 7 & Natural & No Cooling & Offices in residential buildings \\
\hline Type 2 & 41 & Natural & LCS & Offices in residential or multiple floor offices \\
\hline Type 3 & 9 & Mechanical & LCS & Multi floor office buildings \\
\hline Type 4 & 2 & \multicolumn{2}{|c|}{ Central HVAC } & Multi floor office buildings
\end{tabular}

5

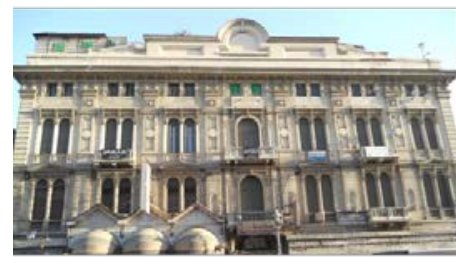

Type 1

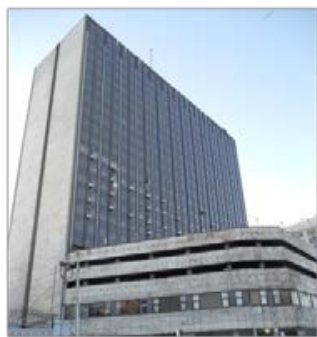

Type 3

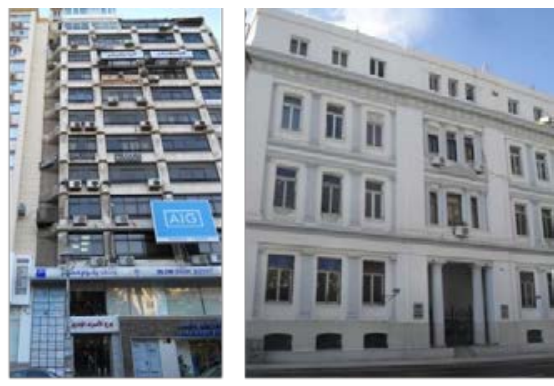

Type 2
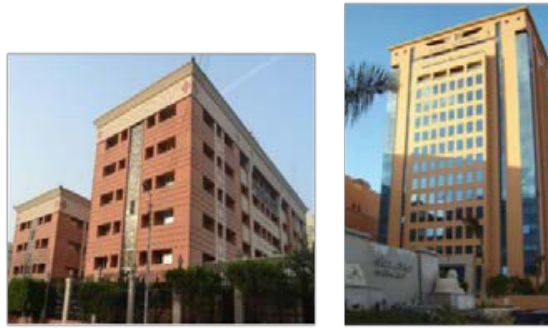

Type 4

Figure 1. Examples of the 4 types of egyptian buildings 

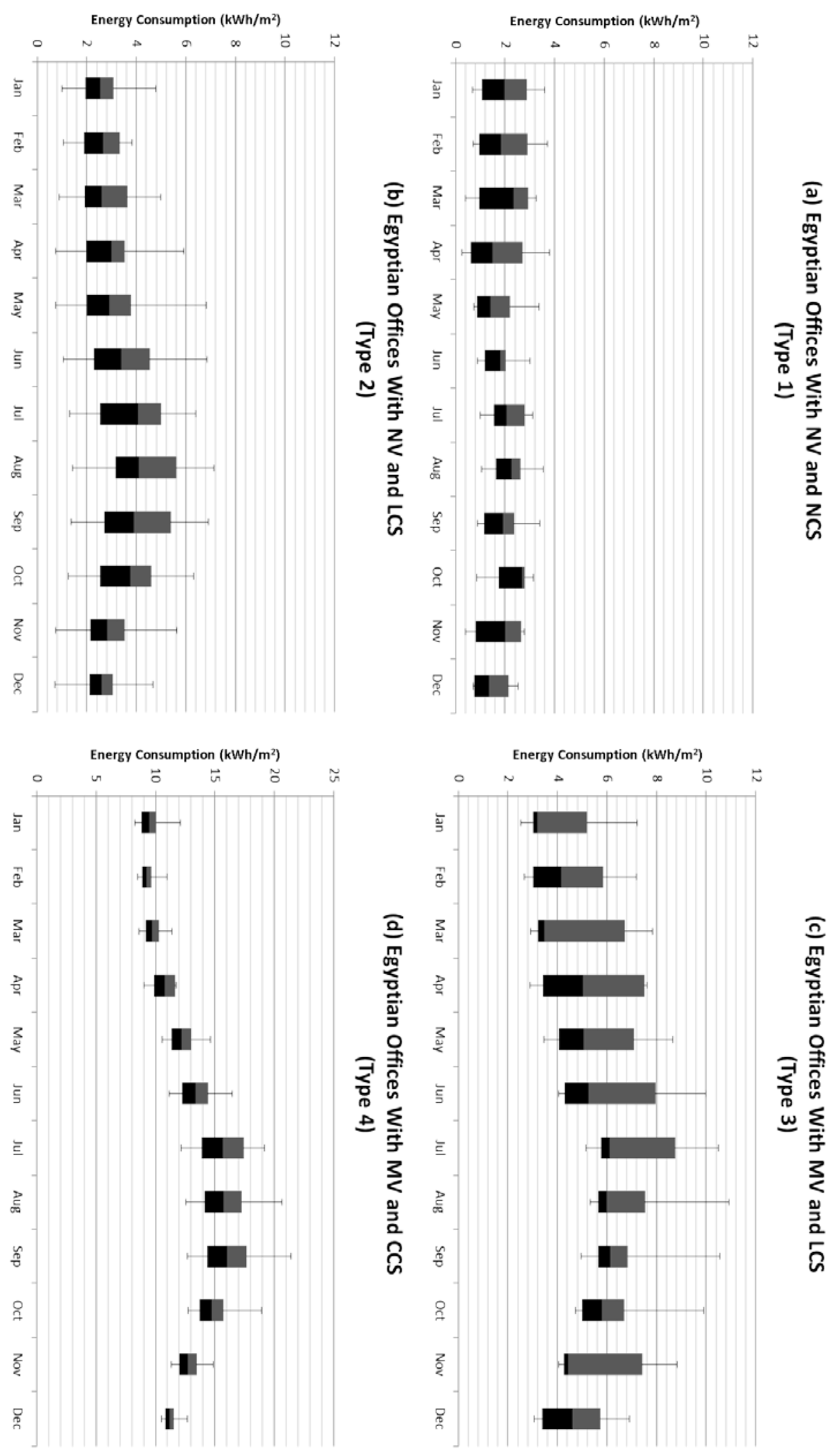

Figure 2. Monthly energy consumption (solid shapes are +/- 25 percentiles, lines the range) for Egyptian offices: (a) with Natural Ventilation (NV) and no cooling, (b) with Natural Ventilation (NV) and Local Cooling System (LCS), (c) with Mechanical Ventilation (MV) and Local Cooling System (LCS), and (d) with Mechanical Ventilation (MV) and Central Cooling System (CCS). 


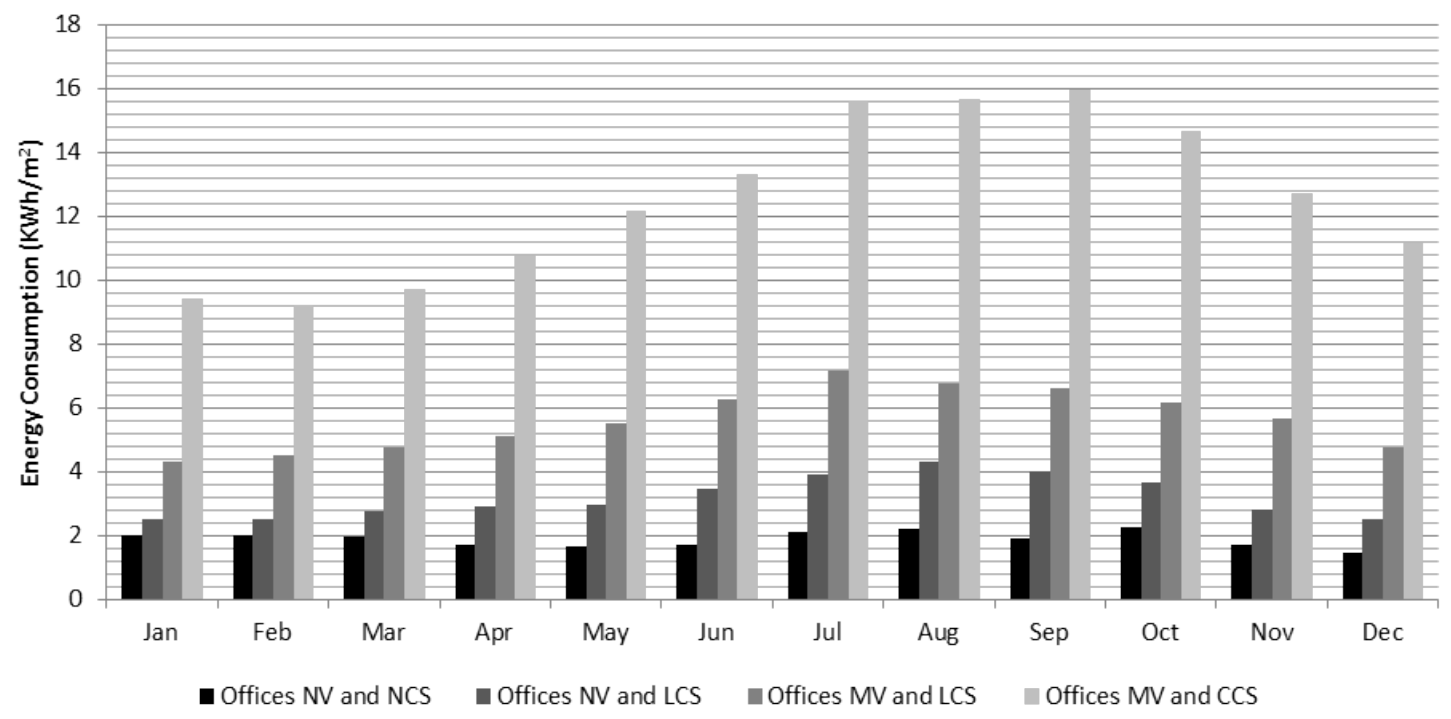

Figure 3. Monthly office energy use vs. service strategy.

Table 2. Average annual electricity consumption for the Egyptian office surveys plus supplementary data from *Abdelhafez [34] and ** Ezzeldin [35]; and comparable ECG 19 [36] data with space heating excluded.

\begin{tabular}{c|c|c|c|c} 
Category by Services & $\begin{array}{c}\text { NV and NCS } \\
\text { (type 1) }\end{array}$ & $\begin{array}{c}\text { NV and LCS } \\
\text { (type 2) }\end{array}$ & $\begin{array}{c}\text { MV and LCS } \\
\text { (type 3) }\end{array}$ & $\begin{array}{c}\text { MV and CCS } \\
\text { (type 4) }\end{array}$ \\
\hline Annual average $\mathrm{kWh} / \mathrm{m}^{2}$ & 23 & 40 & 67 & 150 \\
\hline $\begin{array}{c}\text { ECG19 best practice / } \\
\text { typical }\end{array}$ & $31 / 48$ & $50 / 77$ & $124 / 218$ & $230 / 350$
\end{tabular}

\subsection{Detailed performance investigation for a case study office building.}

The most common office type found in the 59 building survey was 'Type 2' with natural ventilation and local cooling units. A case study building of this type was identified for more detailed energy and indoor environmental evaluation. The steps were to gather general building data, a detailed monitoring exercise, and establish appropriate weather data.

The office building selected is a Human Resources building, constructed in the mid-nineties, serves the "Arab Academy for Science, Technology \& Maritime Transport”. Figure 4 and Figure 5 show the location of the building, internal and external views. Activities follow the academic calendar with increased activities in June and August, Ramadan was July. Total floor area is $1090 \mathrm{~m}^{2}$ with 27 office spaces of variable area. Initial data was collected (Table 3) from available plans and site survey. Infiltration was assumed based on literature [35],[48],[54].

To capture energy and IEQ performance plus occupant behaviour and operations, parameters measured were identified in literature including: temperature, humidity, energy consumption, and $\mathrm{CO}_{2}$ level [27],[28],[55]. Portable devices were used; devices were moved as required to provide coverage. Electricity has 2 supplies, one for lighting, and the second for all other loads including cooling.

Occupants in this type of building have personal control over their environment through adjustments in cooling on/off switch and set-point temperatures, adjustments to windows, doors or blinds, etc. These adjustments affect energy use and IEQ as do the use of lights and other equipment. Large variations in user behaviour were observed. Several offices were monitored internally for temperature, humidity and carbon dioxide including offices labelled as S02, S07 and S08 on the second floor and F10 on the first floor. In addition to physical measurements; parameters such as cooling system set point, occupancy, and clothing level were observed during periodic visits. Office S08 was selected as representative of the most prevalent 'typical' occupied behaviour 
while the other offices illustrate observed variations from this. Figure 6(a) and Figure 6(b) show two different offices in august, both cool their offices continuously during the day but with very different achieved temperatures of around 17 and $24^{\circ} \mathrm{C}$ respectively; Figure 6(c) shows observed behaviour in winter where the cooling was set on at arrival and then turned off after approximately two hours. Capturing the observed variability in user behaviour modelling would appear to present a challenge. The most commonly observed behaviour i.e. similar to office S08, was to set the A/C set point temperature at $21^{\circ} \mathrm{C}$. The relative humidity for different offices was monitored and found to vary between $40 \%$ to $80 \%$ in summer and $65 \%$ to $80 \%$ in winter.

Measured $\mathrm{CO}_{2}$ levels inside the office spaces provide an indirect indicator for both occupant density and occupancy schedule although confounded by air change rate. Figure 7 shows CO2 levels inside the same office that nominally has two occupants for two separate periods, again illustrating high variability.

External observations were taken to quantify use of windows and blinds, high variability was observed office to office, day to day and season to season. The office highlighted in Figure 8(a) and Figure 8(b) has different window and blind configurations on different days, Figure 8(c) shows that blinds and windows are in various positions during a winter day. It was observed that in general the windows were predominantly closed in summer when the A/C is turned on. In intermediate and winter seasons, the windows were sometimes opened, less frequently on cooler days.

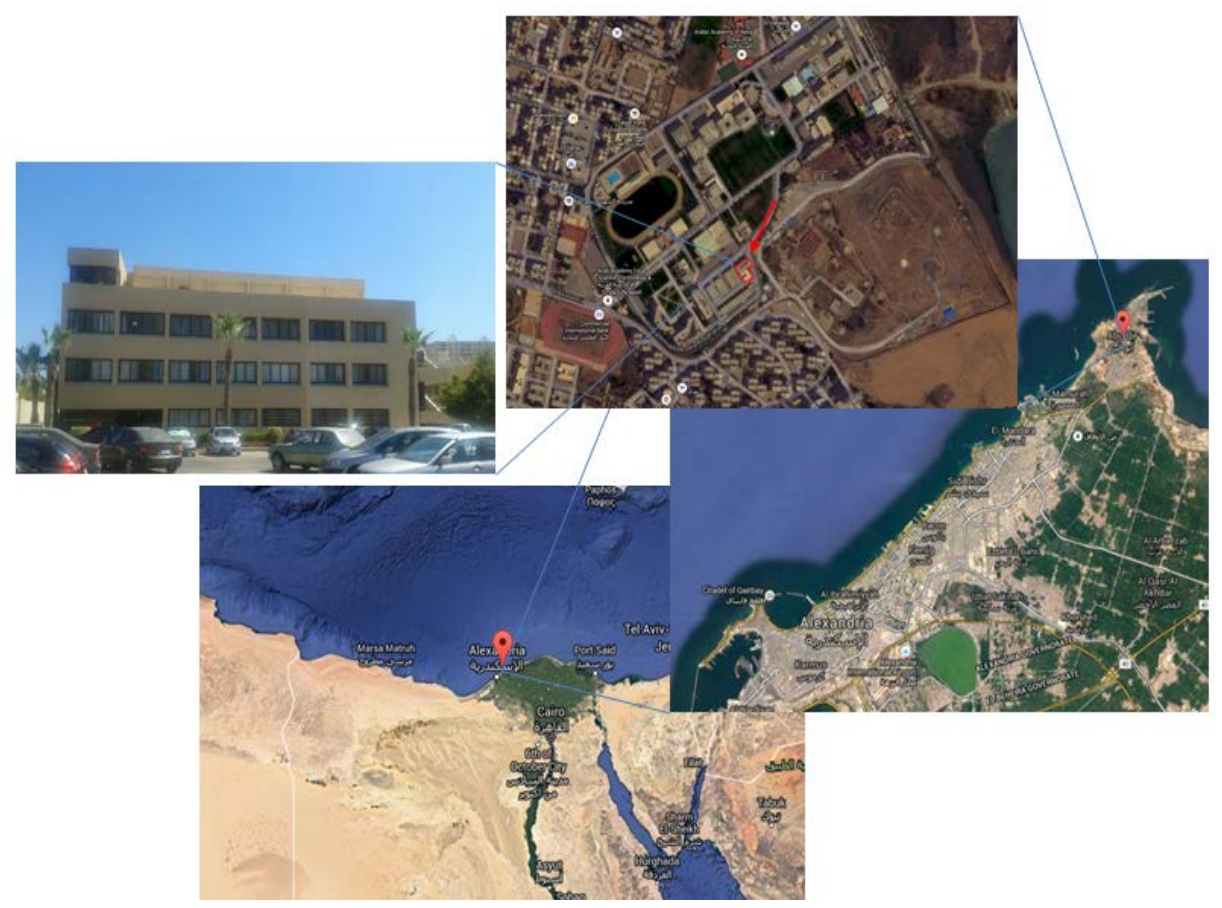

Figure 4. Location and external view of the office building. 


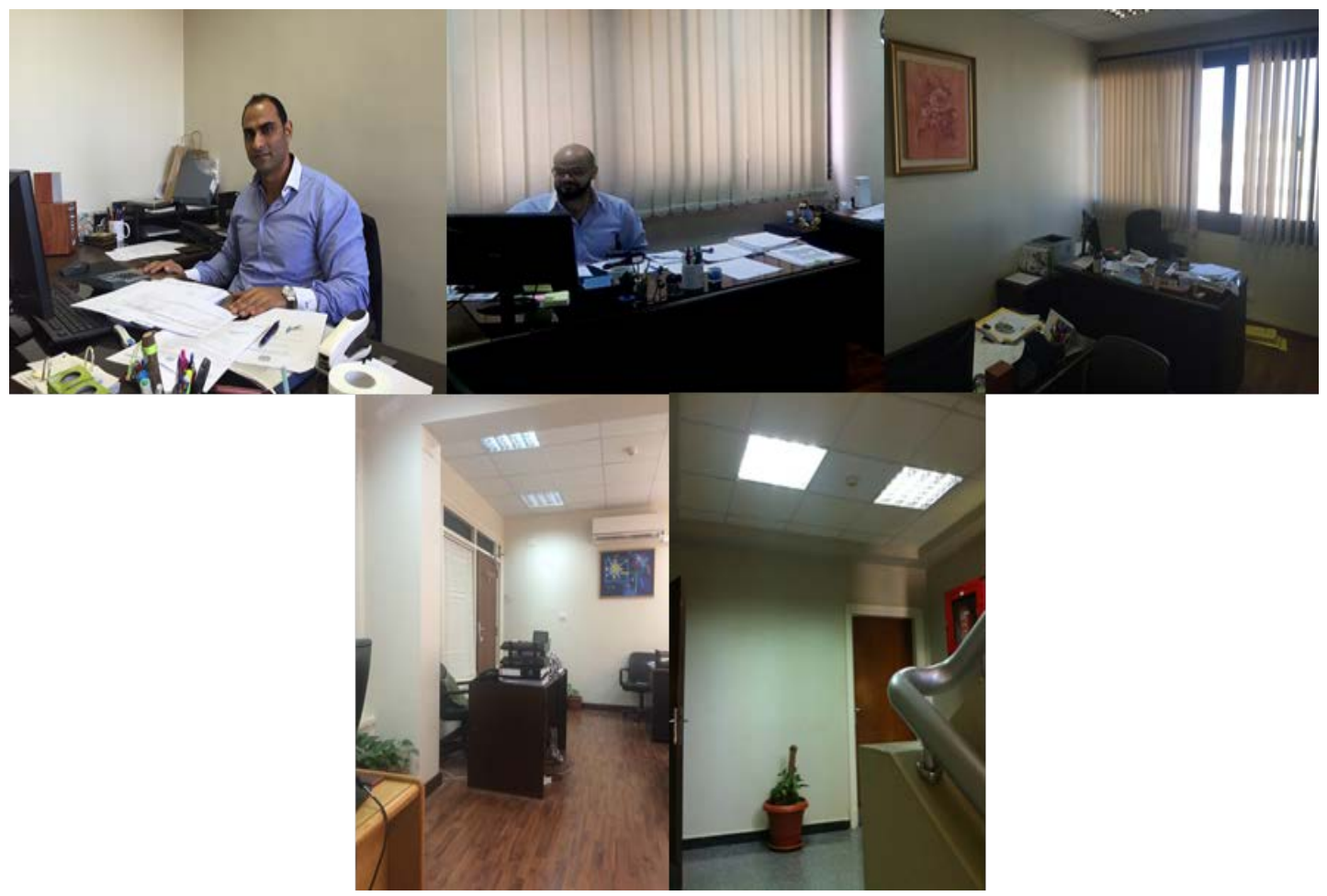

Figure 5. Internal views of the office building

Table 3. Initially estimated occupancy, lighting, equipment, HVAC, and construction parameters.

\begin{tabular}{|c|c|c|c|}
\hline \multicolumn{4}{|c|}{ 1. Occupant Density } \\
\hline Density allocated by workstations & \multicolumn{2}{|c|}{1,2 , or 3 persons } & Occupant / Office \\
\hline $\begin{array}{l}\mathrm{m}^{2} / \text { person for larger office spaces, } \\
\text { assumed 9am-5pm occupancy. }\end{array}$ & \multicolumn{2}{|l|}{10} & $\mathrm{~m}^{2} /$ person \\
\hline \multicolumn{4}{|c|}{ 2. Lighting } \\
\hline Installed Lighting Load & \multicolumn{2}{|l|}{9.00} & $\mathrm{~W} / \mathrm{m}^{2}$ \\
\hline \multicolumn{4}{|c|}{ 3. Equipment } \\
\hline \multirow{2}{*}{$\begin{array}{l}\text { Installed Equipment Loads : per } \\
\text { workstation for small offices, } \\
\text { density for larger office spaces }\end{array}$} & \multicolumn{2}{|l|}{132.00} & W/Workstation \\
\hline & \multicolumn{2}{|l|}{13.2} & $\mathrm{~W} / \mathrm{m}^{2}$ \\
\hline \multicolumn{4}{|c|}{ 4. HVAC } \\
\hline Cooling set point & \multicolumn{2}{|l|}{23.00} & ${ }^{\circ} \mathrm{C}$ \\
\hline Background infiltration rate & \multicolumn{2}{|l|}{0.60} & $1 / \mathrm{s} . \mathrm{m}^{2}$ \\
\hline \multicolumn{4}{|c|}{ 5. Type of Air Conditioning } \\
\hline Air condition type & Model & Capacity & EER W/W \\
\hline Split & Carrier (42vmc18c) & 2.5 H.P & 2.96 \\
\hline \multicolumn{4}{|c|}{ 6. Construction Material } \\
\hline External Wall U-Value & \multicolumn{2}{|l|}{2.35} & $\mathrm{~W} / \mathrm{m}^{2} \cdot \mathrm{K}$ \\
\hline Internal Wall U-Value & \multicolumn{2}{|l|}{2.31} & $\mathrm{~W} / \mathrm{m}^{2} \cdot \mathrm{K}$ \\
\hline Roof U-Value & \multicolumn{2}{|l|}{0.40} & $\mathrm{~W} / \mathrm{m}^{2} \cdot \mathrm{K}$ \\
\hline External glazing U-Value & \multicolumn{2}{|l|}{6.40} & $\mathrm{~W} / \mathrm{m}^{2} . \mathrm{K}$ \\
\hline External glass solar transmittance & \multicolumn{2}{|l|}{0.82} & --- \\
\hline Glass visible transmittance & \multicolumn{2}{|l|}{0.76} & --- \\
\hline
\end{tabular}


(a) Office SO2 (21/8/2014)

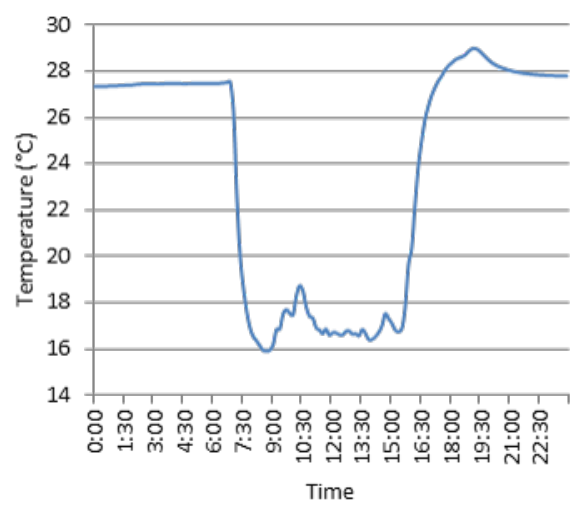

(b) Office S08 (19/8/2014)

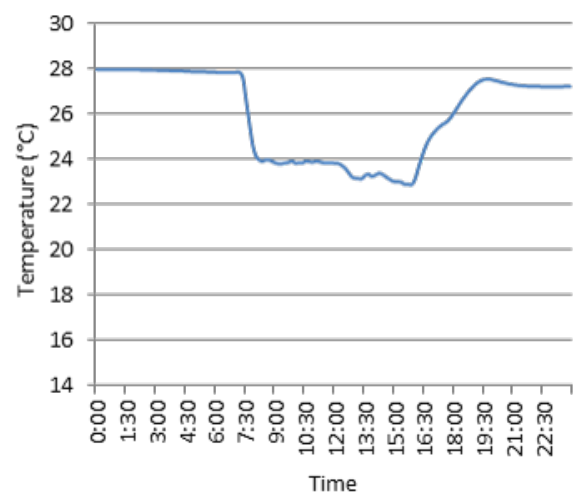

(c) Office F10 (12/11/2014)

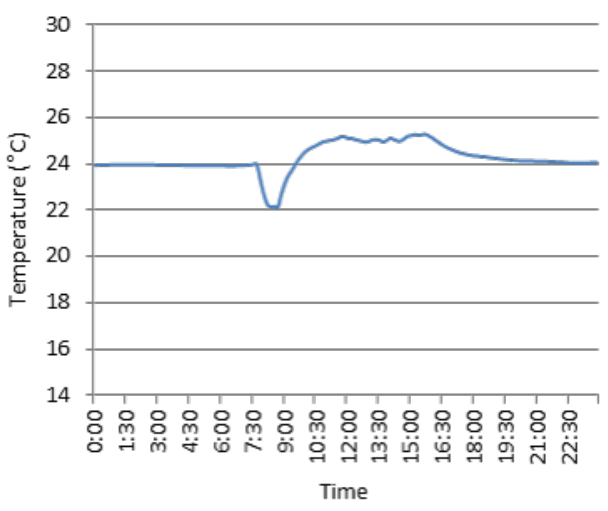

Figure 6. Measured inside room temperature during the day for;

(a) office S02 in August, (c) office S08 in August, and (b) office F10 in November.

(a) Office $\mathrm{S08}$

$(1 / 11 / 2014-6 / 11 / 2014)$

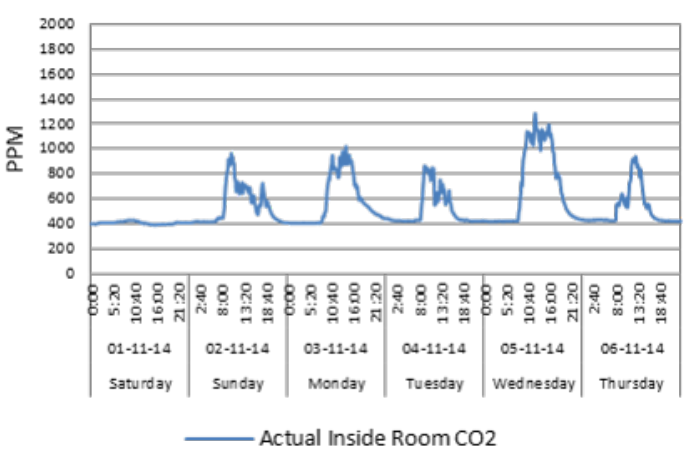

(b) Office S08

$(1 / 12 / 2014-6 / 12 / 2014)$

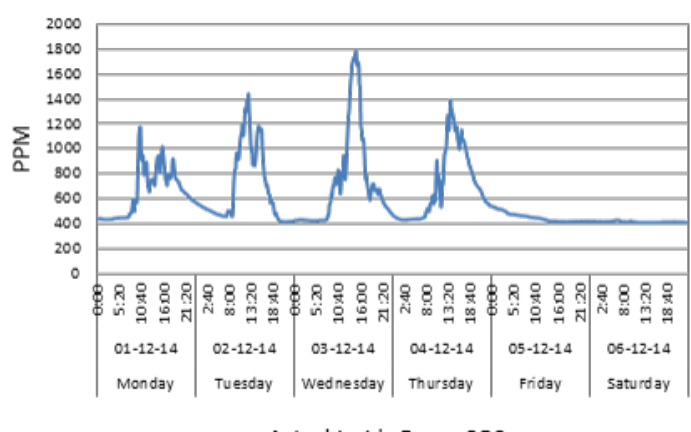

Figure 7. Inside room $\mathrm{CO}_{2}$ level for one of the offices during;

(a) first week of november (2014), and (b) first week of december (2014). 
(a)

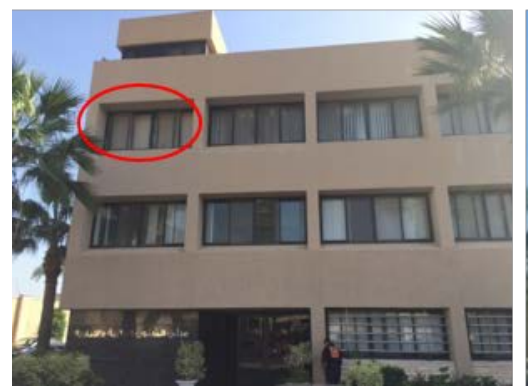

(b)

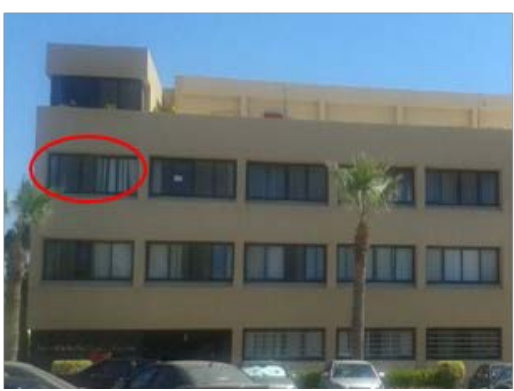

(c)

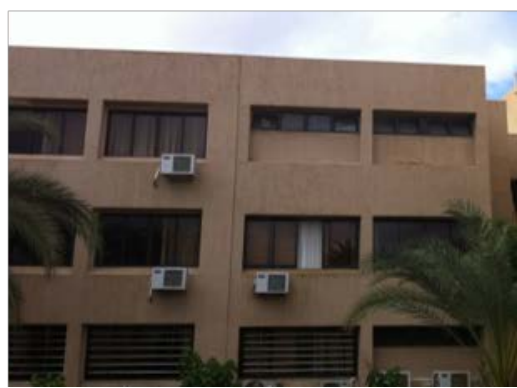

Figure 8. (a) Front side of the building on 07/10/14, (b) Front side of the building on 14/10/14, and (c) Back side of the building on 12/11/14.

The examples discussed above illustrate the variability seen in the monitoring study. Office S08 did appear however to have consistent behaviour and be representative of the most commonly observed behaviour during the survey, with reasonable correspondence in thermal environment with that found in literature associated with thermal comfort [56],[57],[58],[59].

The stochastic variations in behaviours highlighted in this section affect operations, indoor environment and energy use. These variations are challenging to capture in a representative model. Yet it is essential that they are taken into account to ensure the factors behind these variations are represented.

\subsection{Weather.}

The weather for the case study building was important to establish. Alexandria's climate is characterized by a winter moderate season with average temperature around $18{ }^{\circ} \mathrm{C}$ and a summer hot season with average temperature around $28{ }^{\circ} \mathrm{C}$. Hourly temperatures and humidity's for the case study office for 2014, measured at a nearby weather station are shown in Figure 9. Occasional hot winds, known as Khamsin winds, occur and can lead to a temperature rise of $20^{\circ} \mathrm{C}$ in 2 hours [60].

An Egyptian Typical Methodology Year (ETMY) weather file based on long term climate analysis is available for the Alexandria region. This includes the full range of weather parameters in contrast to the local weather station which only records temperature and humidity [61]. To have a full simulation weather file more representative of the actual weather during the monitoring period the measured local temperature and humidity were superimposed on the ETMY weather file. This approach has some inherent limitations, others are investigating methods for synthesising detailed weather files from limited measurement sets [17],[62], but for this work the combined file was deemed to be acceptable and the best currently available.

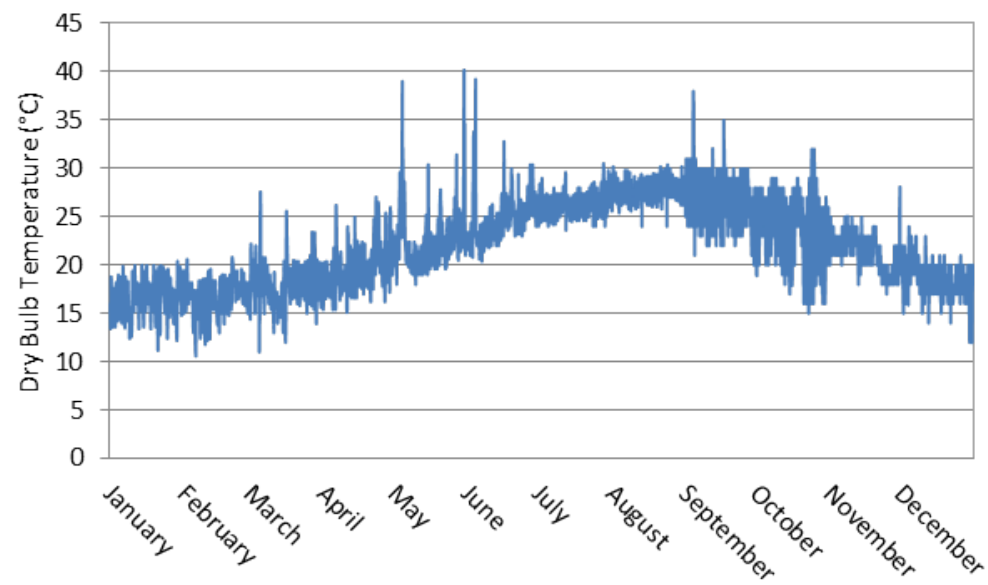

Figure 9. Weather data of Alexandria-Egypt measured by local weather station for year 2014; (dry bulb temperature) 


\subsection{Thermal comfort.}

The driver for behaviour would in some large part be the comfort preferences of the individuals, it is important then to assess what this comfort preference is likely to be. Clothing levels were estimated from observations to be 0.7 CLO in summer and 1.0 in winter with gradual change in transition periods assumed. Figure 10 shows the measured inside dry resultant (operative) temperature for periods when S08 was being measured and its correspondence with the calculated neutral temperature using the non-adaptive Predicted Mean Vote (PMV) equations [63] and an estimate of the mean radiant temperature from building simulation modelling (the model will be described in the following sections). Other, adaptive comfort criteria [56],[64] were evaluated, but the significantly higher indoor comfort temperatures predicted by these methods were not close to the observed situation, PMV gave the best fit and it was proposed that this should be used to represent occupant preference in this work [65]. The applicability or otherwise of the adaptive comfort is revisited later in this paper.

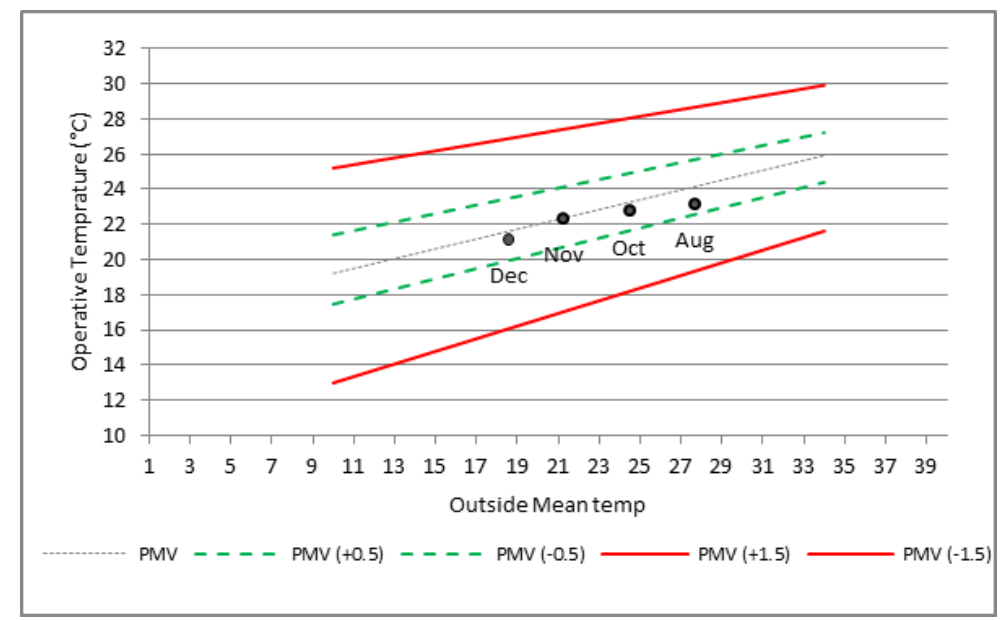

Figure 10. Measured internal conditions for typical office (S08) and PMV comfort criteria versus outdoor mean temperatures.

\section{A modelling framework to represent existing Egyptian offices.}

In order to inform policy and building upgrades using modelling of future scenarios it was necessary to capture the current energy performance of existing Egyptian offices in a modelling framework. This framework should capture the performance of 'typical' offices including the likely range in behaviours and operations associated with the users of the buildings to allow these factors as well as changes in building construction and systems, and variation in weather to be included in assessing future scenarios.

The approach taken to establish such a modelling framework in this work is to first develop a calibrated model for the specific monitored type 2 office building for 'average' observed behaviour then to generalize the model to be more representative of the general type 2 offices from the multi-office survey including input parameter sets to capture likely ranges of operations and behaviours.

\subsection{A calibrated model of the case study type 2 office.}

In order to capture the performance of the monitored building a calibrated sub-hourly dynamic simulation model in IES-VE was created, the modelling details and calibration process are given in detail in a previous paper [53]. The initial behaviours and setpoints were based around the behaviours seen to be most common (i.e. office S08). The calibration process utilized established calibration techniques and criteria [24],[28],[66]. A base model was defined with initial estimates of uncertain input parameters; a parameter screening sensitivity analysis then carried out using this model to identify the order of influence of the input parameters; then a staged individual parameter adjustment process executed to give the best fit. In literature, the criteria commonly used to represent acceptable calibration in a situation where there are significant uncertainties e.g. in user behaviour, is a CV(RMSD) of the order of $30 \%$ [18]. The traditional $\mathrm{R}^{2}$ coefficient was also used as a secondary indicator of goodness of fit.

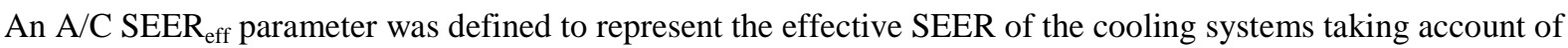
the pattern of local A/C use across the whole building. The effective SEER is calculated from the cooling 
system equipment SEER divided by the diversity factor for A/C use within the building, so if only $50 \%$ of the space is being conditioned at that time then SEER eff $_{\text {is }} 2 \times \mathrm{xEER}$, if only 25\% of the total space is being conditioned and the SEER is 3.5 then the SEER eff $_{\text {is }} 4 \mathrm{x}$ SEER $=14$ etc. There are other approaches to model the $\mathrm{A} / \mathrm{C}$ use pattern but these would have required either more extensive monitoring than was possible and correspondingly more detailed modelling. This parameter represents the situation that was observed where user control of individual cooling systems in individual office spaces means that significantly less energy is used for cooling than would be the case if all spaces were continuously cooled during occupied hours. Modelling was carried out with various proportions of the occupied spaces conditioned to ensure that the results obtained by using the $\mathrm{SEER}_{\text {eff }}$ parameter were realistic. Given the variability seen in cooling system use patterns, the

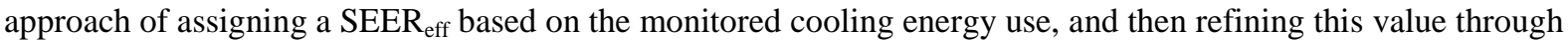
the calibration process, was selected as the best approach.

The parameters included in the sensitivity analysis and ranges were identified based on literature [40],[67],[68]. The initial model was then used to calculate the Influence Co-efficient (IC) [53] for each main uncertain variable. The influence co-efficient was calculated with reference to the energy use. Figure 11 shows the variables with greatest IC for energy use which are: A/C set point temperature, lighting loads, equipment loads,

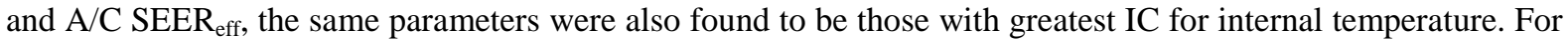
$\mathrm{CO}_{2}$, the variables with greatest IC were infiltration and occupancy.

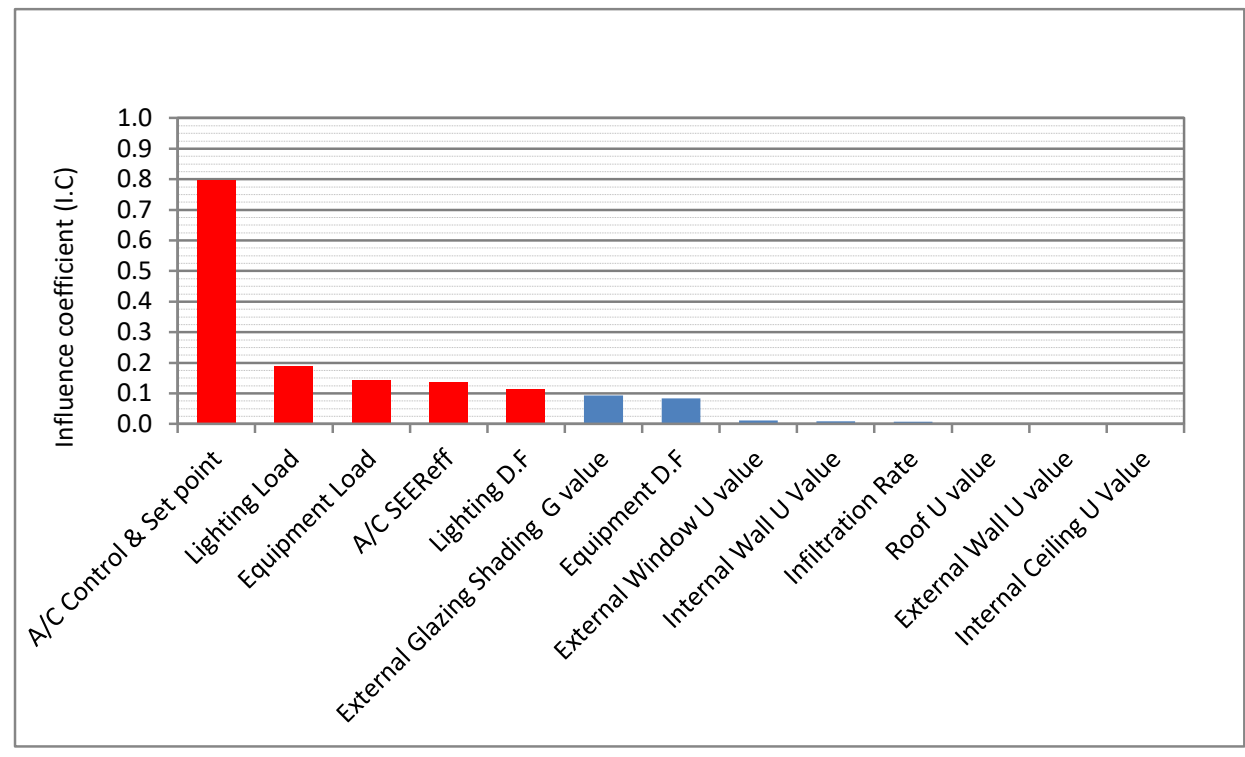

Figure 11. Parametric analysis chart based on the influence coefficient for energy use and indoor temperatures.

Table 4 Primary input parameters and ranges (P.F. = Profile Factor).

\begin{tabular}{|c|c|c|c|c|c|c|}
\hline Parameter & Unit & $\begin{array}{c}\text { Contribution to Power } \\
\text { Consumption }\end{array}$ & $\begin{array}{l}\text { Calibrated } \\
\text { Model }\end{array}$ & $\begin{array}{l}\text { Mean case } \\
\text { Model }\end{array}$ & $\begin{array}{c}\text { Best case } \\
(+3 \text { sigma })\end{array}$ & $\begin{array}{l}\text { Worst case } \\
\text { (-3 sigma) }\end{array}$ \\
\hline $\begin{array}{c}\text { Equipment load } \\
\text { (IT+Miscellaneous) }\end{array}$ & $\mathrm{W} / \mathrm{m}^{2}$ & Positive & 17.6 & 14.8 & 5.9 & 23.7 \\
\hline Equipment P.F. & -- & Positive & $0.6 / 0.9$ & 0.45 & 0.15 & 0.7 \\
\hline Lighting Load & $\mathrm{W} / \mathrm{m}^{2}$ & Positive & 12 & 10 & 4.0 & 16.0 \\
\hline Lighting P.F. & --- & Positive & $0.35 / 0.45$ & $0.3 / 0.5$ & 0.1 & 0.5 \\
\hline Occupancy Load & $\begin{array}{c}\mathrm{m}^{2} / \\
\text { person }\end{array}$ & Negative & 10 & 10 & 16 & 4.0 \\
\hline Occupancy P.F. & --- & Positive & $0.6 / 0.8$ & $0.45 / 0.6$ & 0.15 & 0.7 \\
\hline A/C Set point & ${ }^{\circ} \mathrm{C}$ & Negative & 21 & 22 & 26.0 & 18.0 \\
\hline $\mathrm{A} / \mathrm{C} \mathrm{SEER}_{\mathrm{eff}}$ & W/W & Negative & 6 & 8 & 14.0 & 2.0 \\
\hline Infiltration Rate (Operation) & $\mathrm{l} / \mathrm{s} \cdot \mathrm{m}^{2}$ & Positive & \multirow{2}{*}{1} & 0.5 & 0.1 & 1.0 \\
\hline Infiltration Rate (Envelope) & $1 / \mathrm{s} \cdot \mathrm{m}^{2}$ & Positive & & 0.3 & 0.3 & 0.3 \\
\hline
\end{tabular}


The calibration process was organised into stages. In the first stage, the original base model was used and influencing variable 1 adjusted to give the best fit. In the second stage the updated model used and influencing variable 2 adjusted, and so on. Table 4summarises the calibrated values set for each of the parameters. The calibration process resulted in all variables having CV(RMSE) less than 34\% [53]. Selections of results from the model calibration process are shown in Figure 12 to Figure 16. Figure 12 and Figure 15 show measured and simulated $\mathrm{CO}_{2}$ and temperature for typical conditions for the 'typical' office $\mathrm{S} 08, \mathrm{CO}_{2}$ level is consistent with acceptable levels in standards i.e. 700 to 1000 PPM above outside $\mathrm{CO}_{2}$ level. As indicated in

Figure 13 and Figure 14, there is good agreement with measured data for both lighting and non-lighting energy. Figure 14 shows combined equipment and A/C energy consumption, both measured and simulated, during summer (A/C in use). In general good agreement is achieved between the simulation results and measured data (Figure 16).

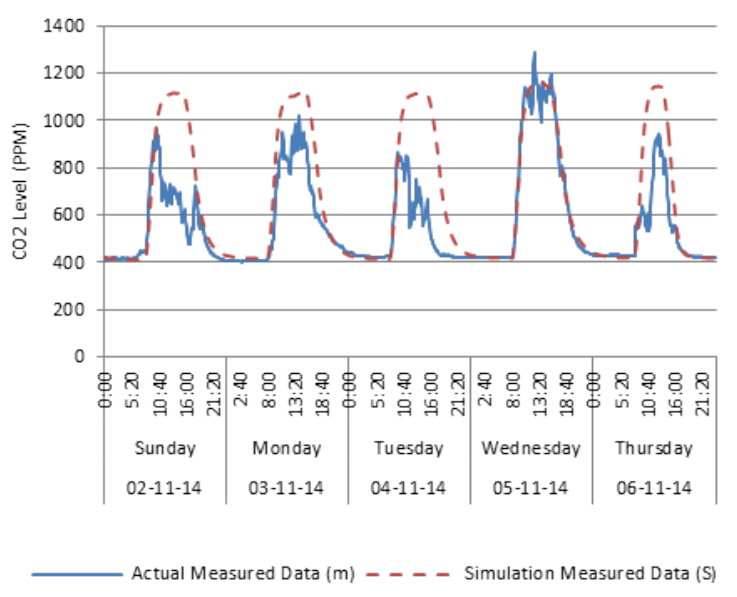

Figure 12 Inside room CO2 level

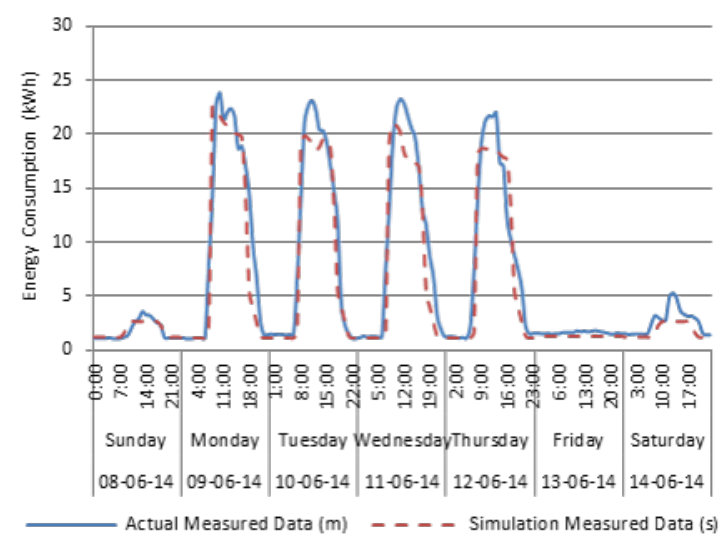

Figure 14 Equip + cooling energy consumption

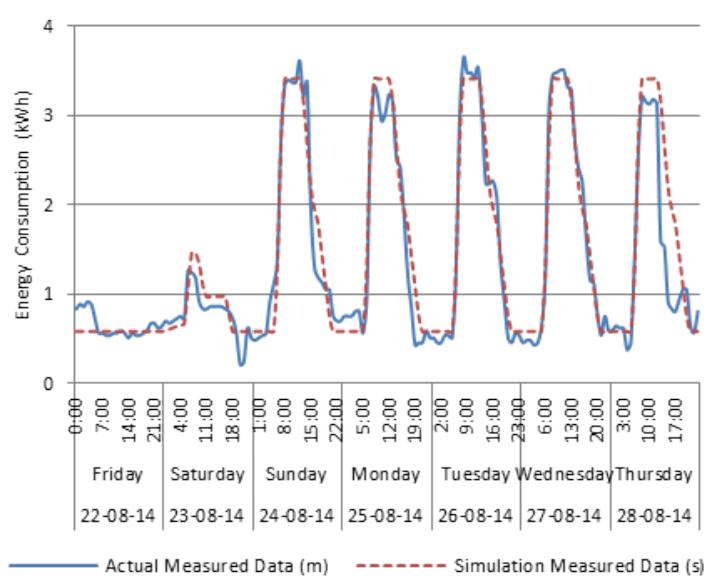

Figure 13 Lighting energy consumption

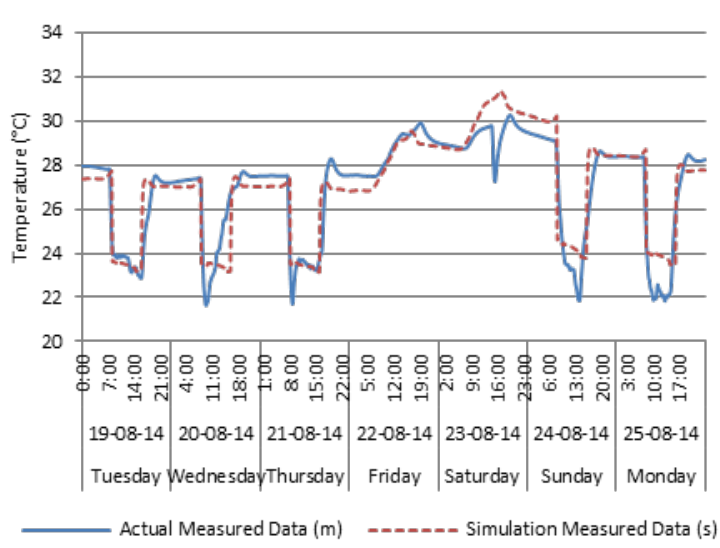

Figure 15 Inside room dry resultant temperature 


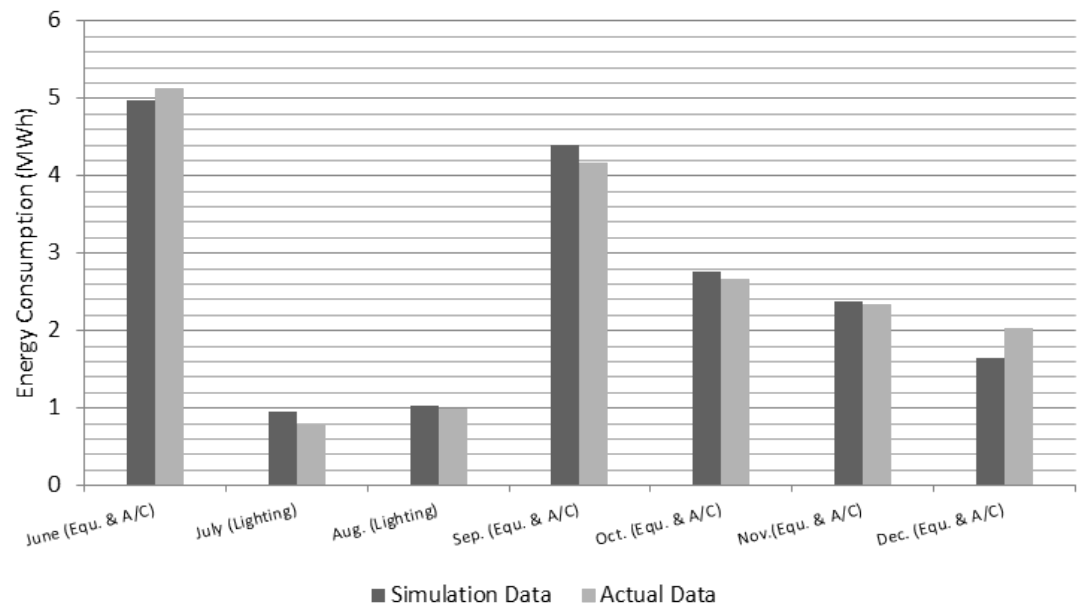

Figure 16. Sample of total equipment and lighting energy consumption.

\subsection{Generalization of the model: Typical model and input parameter ranges.}

A calibrated model based on the average behaviour in the case study building e.g. office S08 is very specific to the context and may not be representative of the general performance of this type of building. The case study building has a different monthly energy use profile from the average observed in the general survey of type 2 offices reported in section 2, shown in Figure 17 (a). The case study building has noticeably higher than average energy use in June and August associated with the intensive academic related activity in these periods. May and September also partly affected. During July there were shorter working hours for Ramadan. Energy use in the winter period is closer to the average of the surveyed offices, generally lying between the upper and lower 25th percentile around the mean.

To make the model more representative of average performance, a more consistent occupancy pattern was implemented, with summer activity levels reduced to the same level as for other months to reflect that the higher summer administrative activities measured in a University Administration building do not represent the majority of offices. The other input parameters were also reviewed and in some cases adjusted to be closer to the mean value of the ranges established from the literature as used previously in the calibration process (Table 4). With these adjustments the model results matched more closely with the mean of the survey data for type 2 offices (Figure 17 (b)). The intensity of occupation has a large impact on office building energy use, typical as well as high and low intensities of occupation are discussed further in section 4.5.

The typical model was re-run without cooling and the results compared against those for the type 1 offices in the survey, this also gave good agreement (Figure 18). Extension of the model to represent more intensively serviced office types will be the focus of further work.
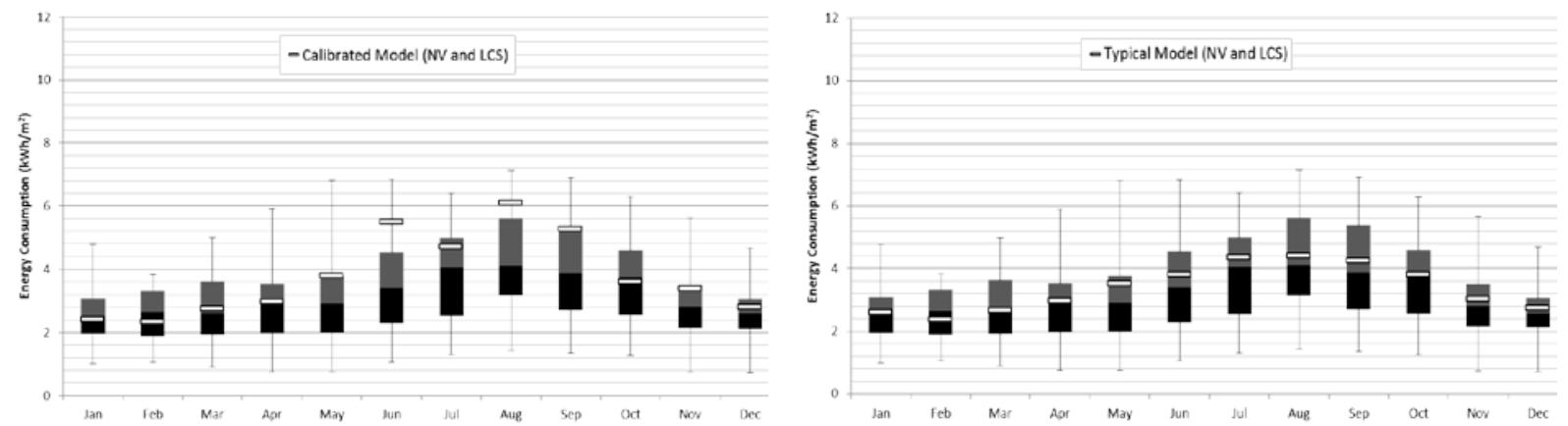

Figure 17. Monthly energy consumption for type 2 offices; (a) survey and calibrated model results, and (b) survey and typical model results. 


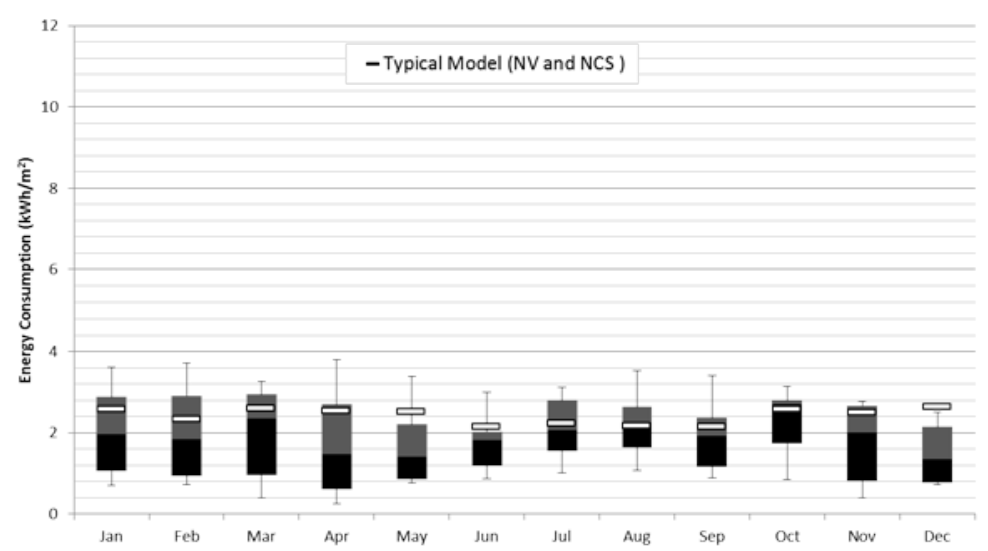

Figure 18 Monthly energy consumption for type 1 offices with Natural Ventilation (NV) and NO Cooling System (NCS): survey and typical model results.

To capture the inherent variability in operation and behaviour, 'best and worst case parameter sets' used in other industries to bracket likely ranges in input parameters were investigated [68]. The ranges previously established for influence coefficient analysis were categorised in terms of their positive or negative influence on energy consumption e.g. increasing equipment loads will positively increase energy consumption, while increasing the cooling set point effect on energy consumption will be negative; and the extremes combined into 'best' and 'worst' case sets which drive low and high energy consumption respectively. The ranges were hypothesised to represent a notional +/- 3 standard deviations imposing a notional normal distribution on each parameter for which the standard deviations can be determined (i.e. range divided by 6).

As the probability of occurrence of combinations where all 10 parameters are all at the same time at the $+/-3$ deviation extreme is very low this is too extreme a situation to consider in modelling, rather the situation where all 10 parameters are at +/- 1 standard deviation best or worst case levels together gives a more realistic spread, as represented in Figure 19.

The worst case model input parameter sets described here give some indication of likely effects of the most influential factors for building performance and in part explain the variation seen in the survey, however to more fully comprehend building energy and IEQ performance a more detailed parametric study is required.

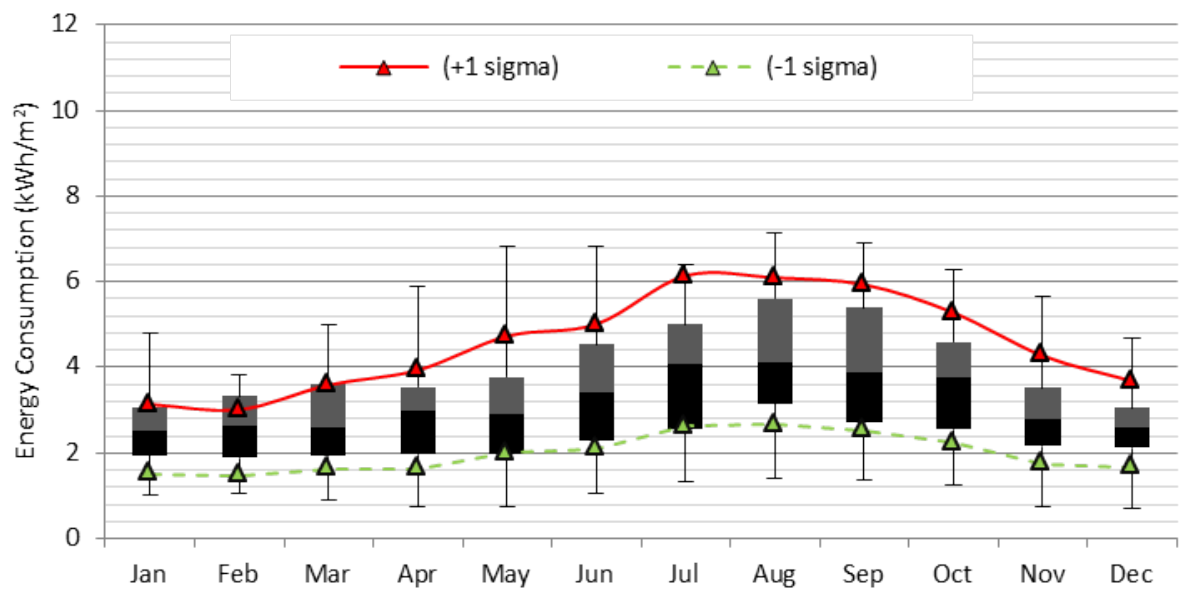

Figure 19. Realistic worst-case model input parameter sets for $+/-1$ standard deviation combinations superimposed on monthly energy consumption for Egyptian type 2 offices.

\section{Input parameters for Energy and IEQ parametric sensitivity study.}

The preceding sections described the underpinning modelling framework representing existing type 2 office performance and showed the influence of some key variables identified in the model calibration. A more 
comprehensive parametric study was then designed to capture variables which had been fixed in the calibration process and also to investigate occupant behaviour in more detail.

To allow the many individual input parameters to be analysed and results displayed in a readily comprehensible manner an initial step was to group input parameters into 6 categories (Figure 10): (i) Location e.g. climate zone within the Egypt; (ii) Weather e.g warm, cool or typical; (iii) Building Envelope e.g. building construction thermal standards; (iv) Installed systems e.g. equipment lights and HVAC; (v) Behaviors in terms of required thermal comfort standard and diligence in switching off when not in use; (vi) Intensity of occupancy in terms of occupant density and occupancy. Probable ranges were then established for input parameters in each of the categories to allow single and combinatorial parametric studies to be carried out to explore their influence on performance.

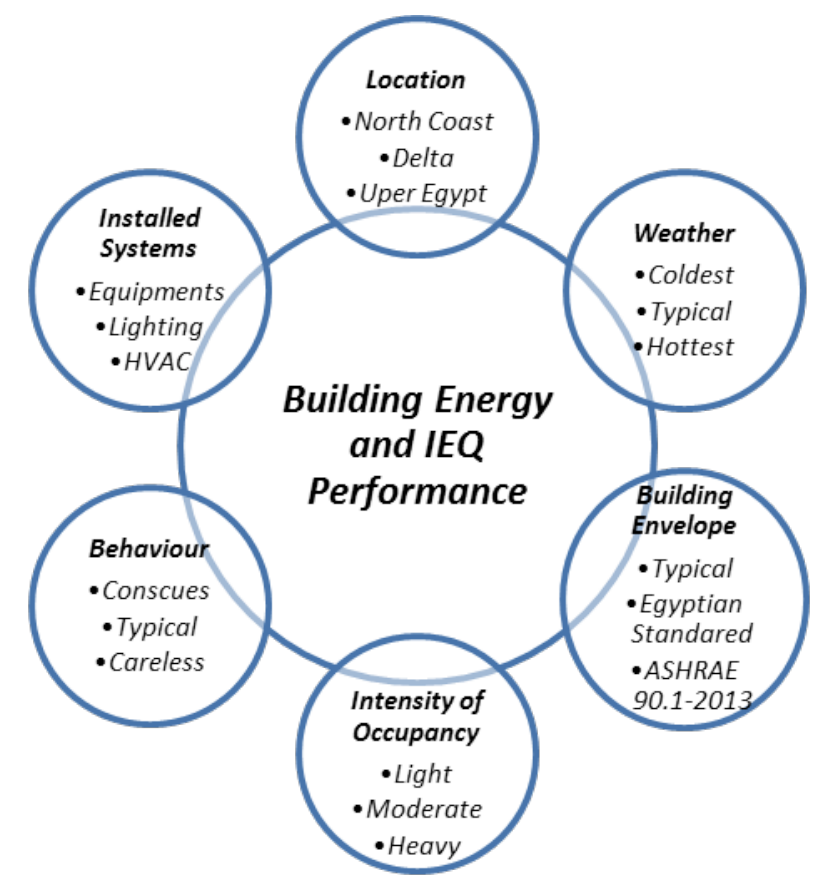

Figure 20 The Ranges of the key drivers of building energy and IEQ

\subsection{Location.}

Egypt is classified in eight regions based on weather in the Egyptian Code for Energy (ECP 306-2005) [69]. Three locations which have high populations were selected for this study i.e. Alexandria City (Northern Coast Zone), Cairo City (Cairo and Delta Zone), and Asyut City (Boundary between Northern and Southern Upper Egypt Zones).

\subsection{Weather.}

Energy and environmental performance studies based on a single selected 'typical' weather year, while they may provide useful insights, do not provide any information about how performance will vary as weather conditions inevitably deviate from those on which studies were based. Much research has been applied to study the variation of the weather file and appropriate methods for capturing this in simulation input files. Several studies proposed using a multi-year weather data to synthesise a 'standard' weather file (Dorm \& Amor(1993) [70], Hui \& Cheung (1997) [71], and Crawley et al. (1999) [72]. More recent studies found limitations in this approach e.g. with respect to overheating calculations [73] leading to the generation of design weather files (Narowski et al. (2013) [74], Georgiou et al . (2013) [75]). Crawley \& Lawrie (2015) developed extreme meteorological year (XMY) weather files to represent the extremes of the climate that the building will experiences [76]. The available data in Egypt was not sufficient to developed XMY weather files based on Crawley et al. (2015) [76, 77] . To create weather files for use in this study the methodology followed was: (i) First available weather files for the last 15 years were collected; (ii) the average maximum \& minimum monthly dry bulb temperatures were used to select for each calendar month the extremes of weather from the dataset; (iii) the weather for the identified extremes for each calendar month was then used to construct the hottest weather file based on the 12 highest extreme months and the coldest weather file based on the 12 at the lower extreme, some manual 
smoothing was applied to transitions between months. Those hottest and coldest years are two extreme years which cover a range of the weather. Due to the limited data available this method has limitations and should be revised when more data becomes available however was chosen as a reasonable representation of the likely weather extremes. Figure 21 show a graph for the two extreme weather files for Alexandria.

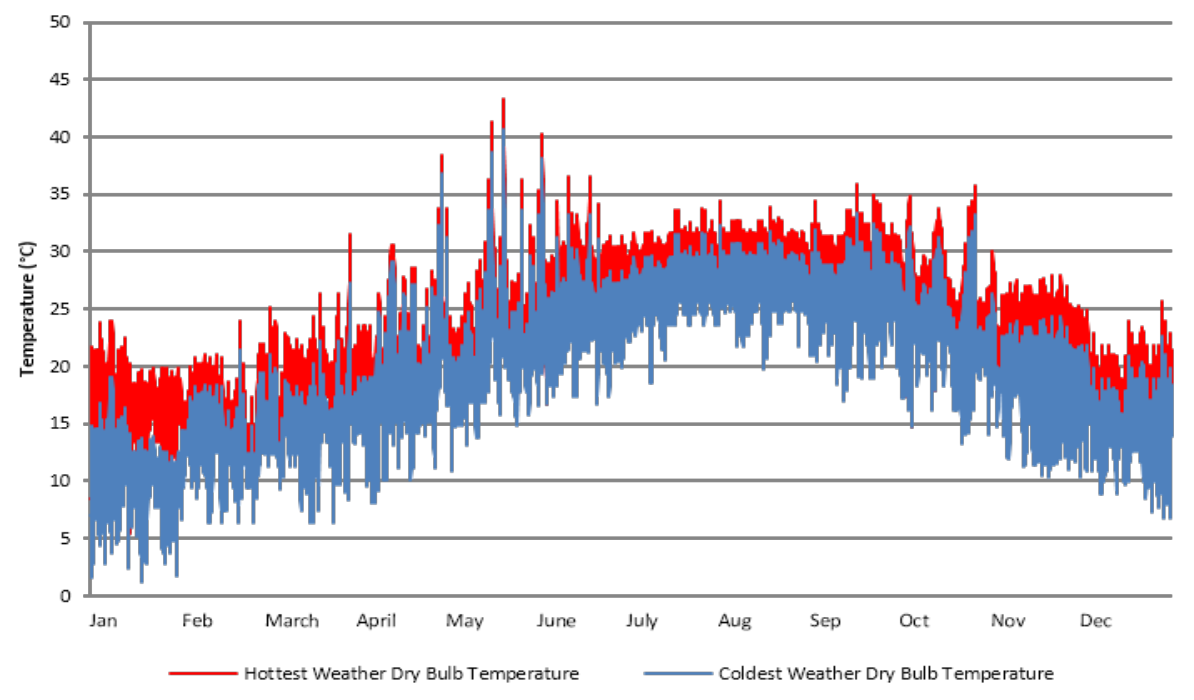

Figure 21 Dry bulb Temperature for Hottest and Coldest Weather File for Alexandria

\subsection{Building Envelope.}

The building envelope transfers heat from and to the surrounding environment. A number of studies have investigated the effect of the building envelope on the cooling and heating loads (Sheta and Sharples (2010) [48], Ali (2014) [78], Fahmy et al. (2014) [69] , Mahdy \& Nikolopoulou (2014) [43]). Based on these studies and the parametric sensitivity analysis during the calibration for the monitored office, four main variables are chosen to be changed: External Roof U-value [44], External Wall U-value [69], External Windows U-value and G-solar [78]. The levels set for these parameters are shown in Table 5. They have been aligned with the 'typical (type 2 model)', Egyptian code (ECP306/2005), and ASHRAE 90.1-2013. ASHRAE 2010 parameter values are also shown in Table 5as a further reference point.

Table 5 Building Envelope Categories

\begin{tabular}{|c|c|c|c|c|}
\hline Variable & Typical & $\begin{array}{c}\text { EGYPTAIN } \\
\text { CODE (ECP 2005) }\end{array}$ & $\begin{array}{l}\text { ASHRAE 90.1- } \\
2010\end{array}$ & $\begin{array}{c}\text { ASHRAE 90.1- } \\
2013\end{array}$ \\
\hline \multirow{3}{*}{$\begin{array}{c}\text { ROOF } \\
\text { U-VALUE } \\
\left(\mathrm{W} / \mathrm{m}^{2} \cdot \mathrm{K}\right) \\
\end{array}$} & \multirow{3}{*}{0.4} & Alex 0.454 & \multirow{3}{*}{0.28} & \multirow{3}{*}{0.22} \\
\hline & & Cairo 0.454 & & \\
\hline & & Asyut 0.3125 & & \\
\hline \multirow{3}{*}{$\begin{array}{c}\text { EXTERNAL WALL } \\
\text { U-VALUE } \\
\left(\mathrm{W} / \mathrm{m}^{2} . \mathrm{K}\right)\end{array}$} & \multirow{3}{*}{2.35} & Alexandria 1.11 & \multirow{3}{*}{0.85} & \multirow{3}{*}{0.85} \\
\hline & & Cairo 0.714 & & \\
\hline & & Asyut 0.588 & & \\
\hline $\begin{array}{c}\text { EXTERNAL GLAZING } \\
\text { U-VALUE } \\
\left(\mathrm{W} / \mathrm{m}^{2} \cdot \mathrm{K}\right)\end{array}$ & 6 & 5 & 4.250 & 3.69 \\
\hline $\begin{array}{c}\text { EXTERNAL GLAZING } \\
\text { G-VALUE } \\
(\%)\end{array}$ & 0.82 & 0.3 & 0.25 & 0.25 \\
\hline
\end{tabular}

\subsection{Installed Loads and systems.}

Installed system efficiencies are one of the key drivers for energy use and comfort in offices. Technological advancements have allowed for higher efficiency equipment, yet working practices are demanding more use of 
digital equipment. Office installed plug loads and lighting densities are considered to vary based on both installed density and installed system efficiency. The ranges considered in the parametric study are set at the $+/-$ 2 sigma extremes based on the earlier review (Table 6).

Similarly, the efficiency of the HVAC systems has a fundamental impact on the energy performance. For the type 2 offices the SEER of the cooling system has an effect in combination with the pattern of use associated with the cooling system. SEER values of 3, 3.5 and 4 were selected to represent the current range of low cost unitary and split systems (Table 6).

Table 6 Installed Systems Efficiency Categories

\begin{tabular}{c|c|c} 
High Efficiency & Typical & Low Efficiency \\
\hline Equipment $\left(8.9 \mathrm{~W} / \mathrm{m}^{2}\right)$ & Equipment $\left(14.8 \mathrm{~W} / \mathrm{m}^{2}\right)$ & Equipment $\left(20.6 \mathrm{~W} / \mathrm{m}^{2}\right)$ \\
Lighting $\left(6 \mathrm{~W} / \mathrm{m}^{2}\right)$ & Lighting $\left(10 \mathrm{~W} / \mathrm{m}^{2}\right)$ & Lighting $\left(14 \mathrm{~W} / \mathrm{m}^{2}\right)$ \\
SEER $(4 \mathrm{~W} / \mathrm{W})$ & SEER $(3.5 \mathrm{~W} / \mathrm{W})$ & SEER $(3 \mathrm{~W} / \mathrm{W})$
\end{tabular}

\subsection{Intensity of Occupation.}

In office building Intensity of occupancy varies according to the nature of the work in the offices. Some offices are continuously fully occupied with heavy computer and equipment use, lights on and cooling system required to be continuously on while others are occupied only for a small part of the work time, have low computer use and lights and cooling only applied during part of the occupied times. Ranges in diversity factors were applied to represent intensity of occupation (Table 7). The cooling Usage Factor represents the diversity factor multiplied by the percentage of the total internal floor area covered by cooling (many office buildings have local cooling in office spaces but no cooling systems implemented in corridors, stairs, wc's etc.).

Table 7 Catagories of Intensity of Occupancy

\begin{tabular}{c|c|c} 
Light & Typical & Heavy \\
\hline Equipment D.F (0.3) & Equipment D.F (0.6) & Equipment D.F (0.9) \\
Lighting D.F (0.3) & Lighting D.F (0.6) & Lighting D.F (0.9) \\
Occupancy D.F (0.3) & Occupancy D.F (0.6) & Occupancy D.F (0.9) \\
Cooling usage Factor (0.3) & Cooling Usage Factor (0.45) & Cooling Usage Factor (0.75)
\end{tabular}

\subsection{Behavior.}

Most of The current energy performance calculation methods focus primarily on building characteristics delivering a theoretical energy consumption for a standard user. However actual energy consumption may differ greatly from this predicted theoretical consumption. [79] Occupant behavior in buildings has multiple aspects including desire for comfortable surroundings and interactions with building systems to restore comfort if needs are not met. Some occupants may be careless in their use of building systems leading to higher energy use, others may be conscious of the need to reduce energy and how to interact with the building in order to achieve this, some may be restricted in their use of adaptive opportunities by physical or cultural constraints. To capture the likely variation in occupant behavior three scenarios were used (Energy conscious behavior; Typical behavior; Energy careless behavior) as described in Table 8 [80]. Seasonal adaption in clothing levels as described in the model calibration process was not varied between the scenarios but is discussed later.

\section{Combinatorial Parametric Performance Analysis}

A full factorial of the 729 parameter level combinations was then run using the typical model as base. Figure 22 to Figure 27 show various snapshots for Alexandria location. The Y axis represents outputs: total energy use (Figure 22 and Figure 23); average thermal comfort (summer and winter, Figure 24 and Figure 25) ; average CO2 concentrations during occupied hours (Figure 26 and Figure 27). The vertical range within box-plot represents intensity of occupation. Other input variables are captured along the x-axes. The results for energy use are also summarised in Table 9.

Figure 22 shows energy consumption outputs for typical weather and building envelope for various combinations of system efficiencies and behaviours. The best case combination (energy conscious behaviour and high efficiency systems) shows the best performance (e.g. $19.2 \mathrm{kWh} / \mathrm{m} 2$ per year for average intensity of 
operations) while the worst case combination (careless behaviour and low efficiency systems) shows the worst performance (e.g. $76.6 \mathrm{kWh} / \mathrm{m} 2$ per year for average intensity of operations). For average intensity of operations these two factors (efficiency of installed systems and behaviours) can account for around a $4 \mathrm{X}$ difference in energy use. Figure 23 illustrates a relatively smaller effect of weather on energy use.

Table 8 Categories of Behavior

\begin{tabular}{|c|c|c|c|c|}
\hline \multicolumn{2}{|c|}{ Occupant Behavior } & Conscious Behavior & Typical Behavior & Careless Behavior \\
\hline \multicolumn{2}{|c|}{ Cooling Set Point $\left({ }^{\circ} \mathrm{C}\right)$} & 25 & 22 & 19 \\
\hline \multicolumn{2}{|c|}{ Heating Set Point $\left({ }^{\circ} \mathrm{C}\right)$} & No Heating System & No Heating System & No Heating System \\
\hline \multicolumn{2}{|c|}{ Occupant Control: Lightsand Equipment } & $\begin{array}{l}\text { If occupied: } 20 \% \\
\text { dimming of lights in } \\
\text { summer days. } \\
\text { If unoccupied: IT, } \\
\text { equipment, lights, } \\
\text { and cooling off. }\end{array}$ & $\begin{array}{l}\text { If unoccupied: } 10 \% \\
\text { of IT, Equipment } \\
\text { and Lights on. }\end{array}$ & $\begin{array}{l}\text { If unoccupied: } 20 \% \\
\text { of IT, Equipment } \\
\text { and Lights on. }\end{array}$ \\
\hline \multicolumn{2}{|c|}{ HVAC Operation Period } & April to November & $\begin{array}{l}\text { January to } \\
\text { December }\end{array}$ & $\begin{array}{l}\text { January to } \\
\text { December }\end{array}$ \\
\hline \multirow{3}{*}{$\begin{array}{c}\text { External Window } \\
\text { Opening - office areas }\end{array}$} & Summer & $\begin{array}{l}\text { If unoccupied, } \\
\text { windows closed. } \\
\text { If occupied, } \\
\text { windows closed } \\
\text { while A/C ON }\end{array}$ & $\begin{array}{l}\text { If unoccupied, } \\
\text { windows closed. } \\
\text { If occupied, } \\
\text { windows closed } \\
\text { while A/C ON }\end{array}$ & $\begin{array}{l}\text { If unoccupied, } \\
\text { windows closed. } \\
\text { If occupied, } 20 \% \\
\text { of windows open } \\
\text { while A/C ON }\end{array}$ \\
\hline & & $\begin{array}{l}\text { If unoccupied,or AC } \\
\text { ON: windows } \\
\text { closed. }\end{array}$ & $\begin{array}{l}\text { If unoccupied, or } \\
\text { AC ON: windows } \\
\text { closed. }\end{array}$ & $\begin{array}{l}\text { If unoccupied, or } \\
\text { AC ON: windows } \\
\text { closed. }\end{array}$ \\
\hline & Winter & $\begin{array}{l}\text { If occupied and AC } \\
\text { OFF: } 20 \% \text { of } \\
\text { windows open when } \\
\text { room } T>20 \text { and } \\
\text { outside } T<21\end{array}$ & $\begin{array}{c}\text { If occupied and AC } \\
\text { OFF: } 20 \% \text { of } \\
\text { windows open } \\
\text { when } \\
\text { room } T>20 \text { and } \\
\text { outside } T<21\end{array}$ & $\begin{array}{l}\text { If occupied and AC } \\
\text { OFF: } 20 \% \text { of } \\
\text { windows open } \\
\text { when } \\
\text { room } T>20 \text { and } \\
\text { outside } T<21\end{array}$ \\
\hline \multicolumn{2}{|c|}{ Service Window Opening (WCs) } & $10 \%$ open. & 10\% open & 10\% open \\
\hline \multirow{2}{*}{$\begin{array}{c}\text { Background } \\
\text { Infiltration } \\
\text { (envelope+operations) }\end{array}$} & Envelope & $0.3 \mathrm{~L} / \mathrm{S} / \mathrm{m}^{2}$ & $0.3 \mathrm{~L} / \mathrm{S} / \mathrm{m}^{2}$ & $0.3 \mathrm{~L} / \mathrm{S} / \mathrm{m}^{2}$ \\
\hline & operation & $0.2 \mathrm{~L} / \mathrm{S} / \mathrm{m}^{2}$ & $0.5 \mathrm{~L} / \mathrm{S} / \mathrm{m}^{2}$ & $0.8 \mathrm{~L} / \mathrm{S} / \mathrm{m}^{2}$ \\
\hline
\end{tabular}

Figure 24 \& Figure 25 show summer and winter average PPD during occupied periods. PPD was calculated based on summer clothing level 0.7 and winter clothing level 1.0 with assumed metabolic rate of 1.2 met and local air speed $0.15 \mathrm{~m} / \mathrm{s}$. PPD levels show poorer predicted thermal comfort for both the energy conscious and energy careless behaviour cases for 'slightly warm' PMV reasons in summer and 'slightly cool' reasons in winter.

Figure 26 \& Figure 27 show summer and winter $\mathrm{CO}_{2}$ levels respectively. The main effect seen here is due to the different window opening behaviours affecting overall ventilation rates. This highlights the potential conflict between indoor air quality and energy use in buildings which will be discussed further later. All of the average values fall within the range seen in the building survey and within the documented 'acceptable' $\mathrm{CO}_{2}$ range for existing buildings [81].

Figure 28 shows the energy use across the full range of input parameters in the form of energy use indices. Similar to weather, location has a relatively small effect w.r.t. overall variation.

Other HVAC strategies were also modelled applied to the typical type 2 model. The type 1 was modelled by eliminating the cooling systems. Central mechanical ventilation with and without central cooling was applied to represent type 3 and type 4 respectively. For the type 4 case the whole floor area of the office building was conditioned during occupied hours (i.e. cooling usage factor $=1$ ).

To provide a useful overview the results were then aggregated into a set of single base multivariate charts such as that shown in Figure 29. 


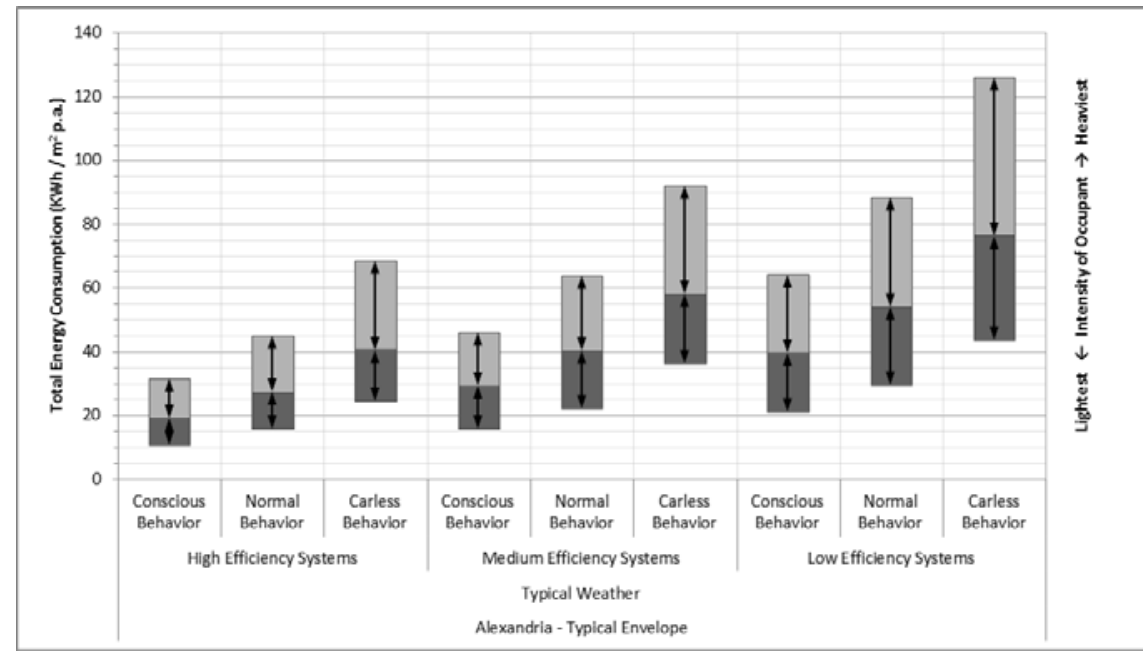

Figure 22 Total Annual Energy Consumption per Unit Area for Alexandria (Typical Construction, Typical Weather)

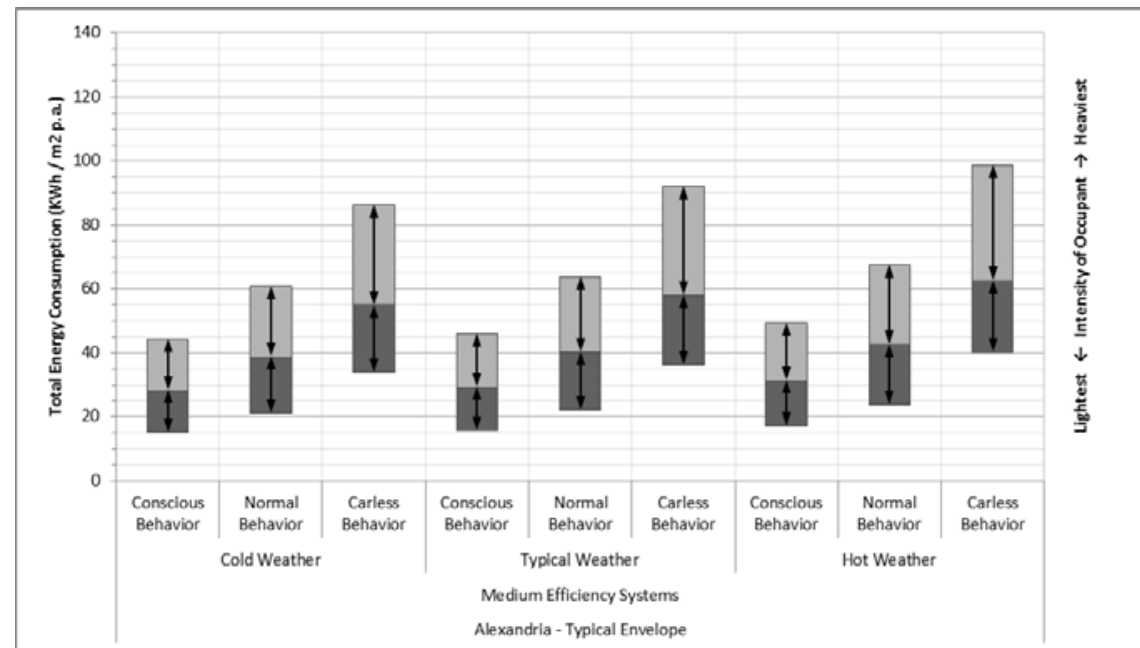

Figure 23 Total Annual Energy Consumption Per Unit Area for Alexandria (Typical Construction, Medium Efficiencies)

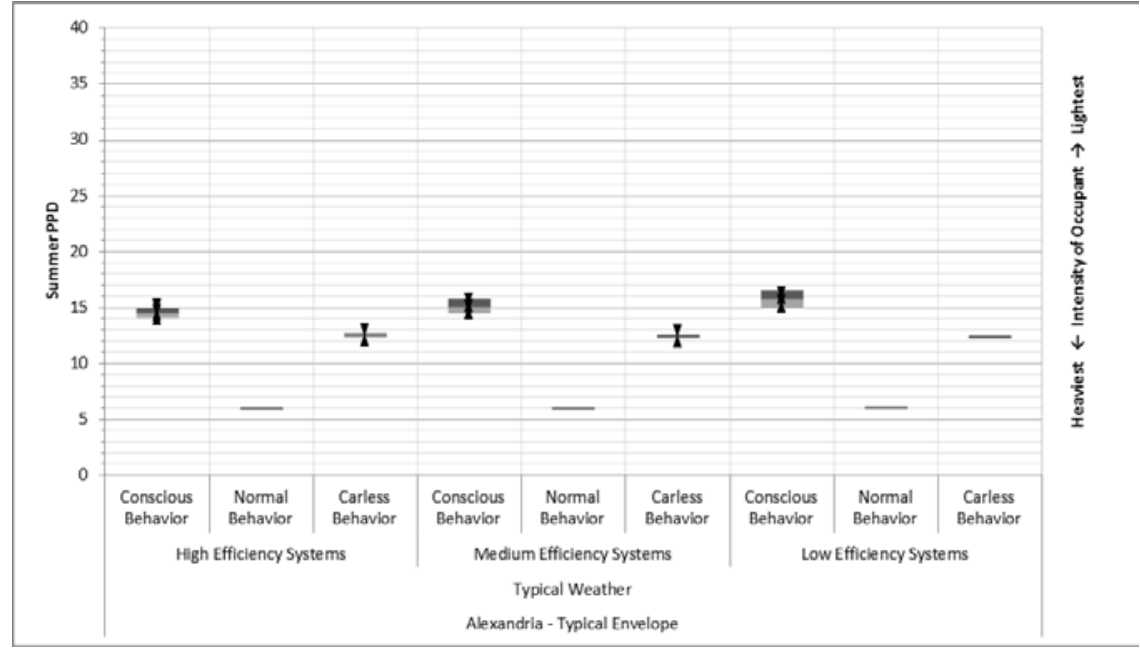

Figure 24 Summer PPD for Alexandria (Typical Construction, Typical Weather) 


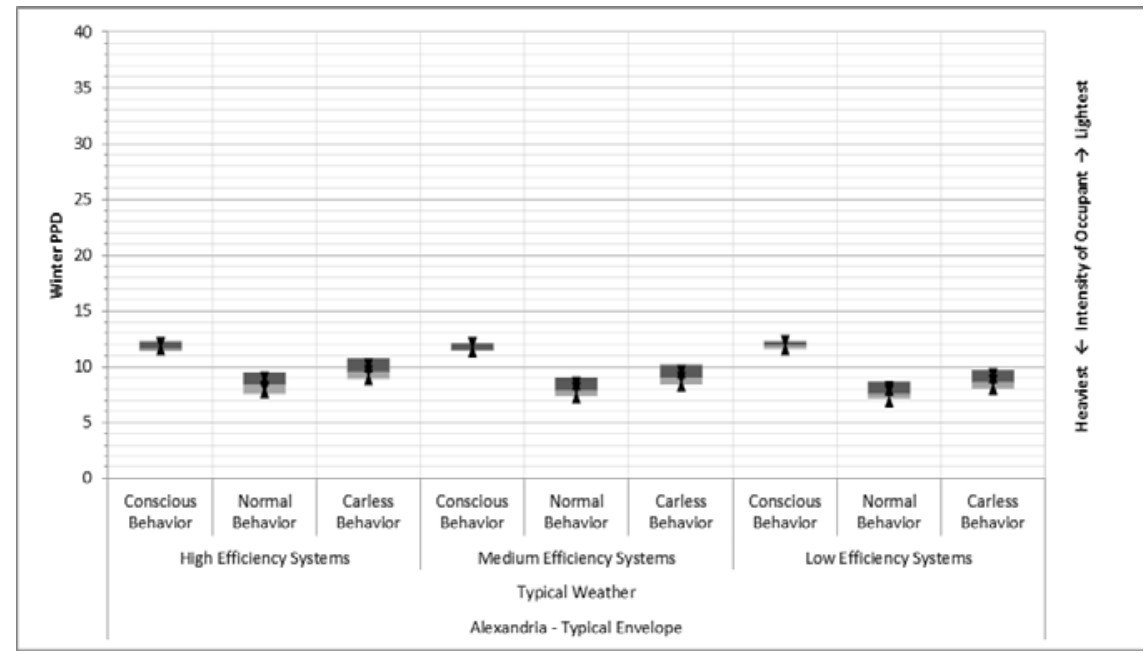

Figure 25 Winter PPD for Alexandria (Typical Construction, Typical Weather)

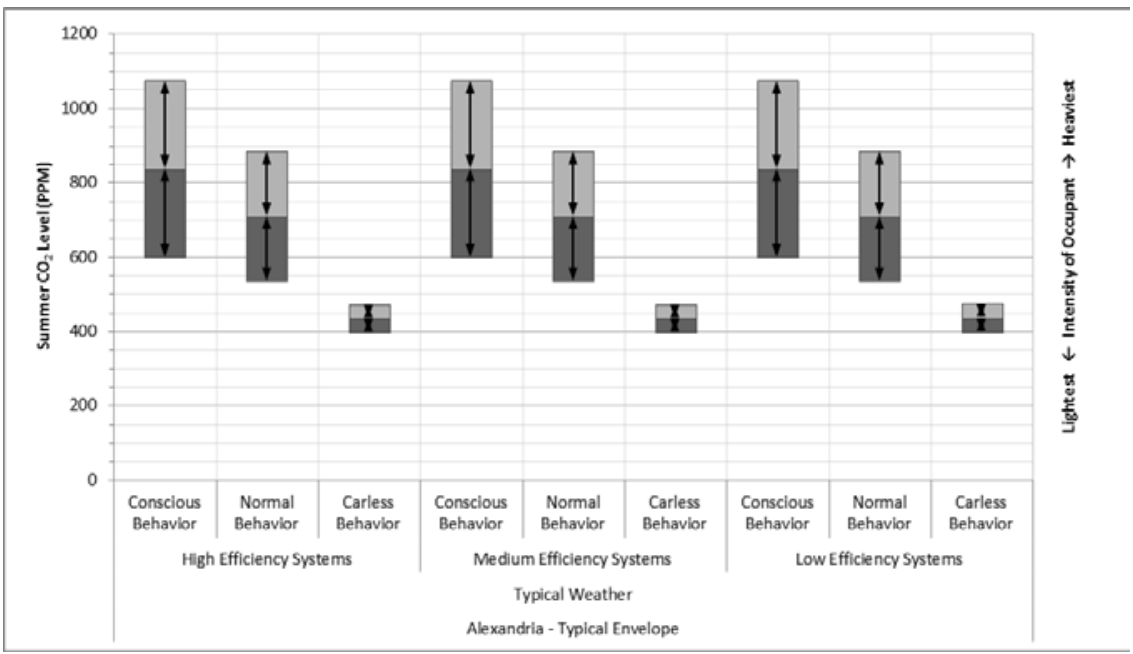

Figure 26 Summer CO2 Level for Alexandria (Typical Construction, Typical Weather)

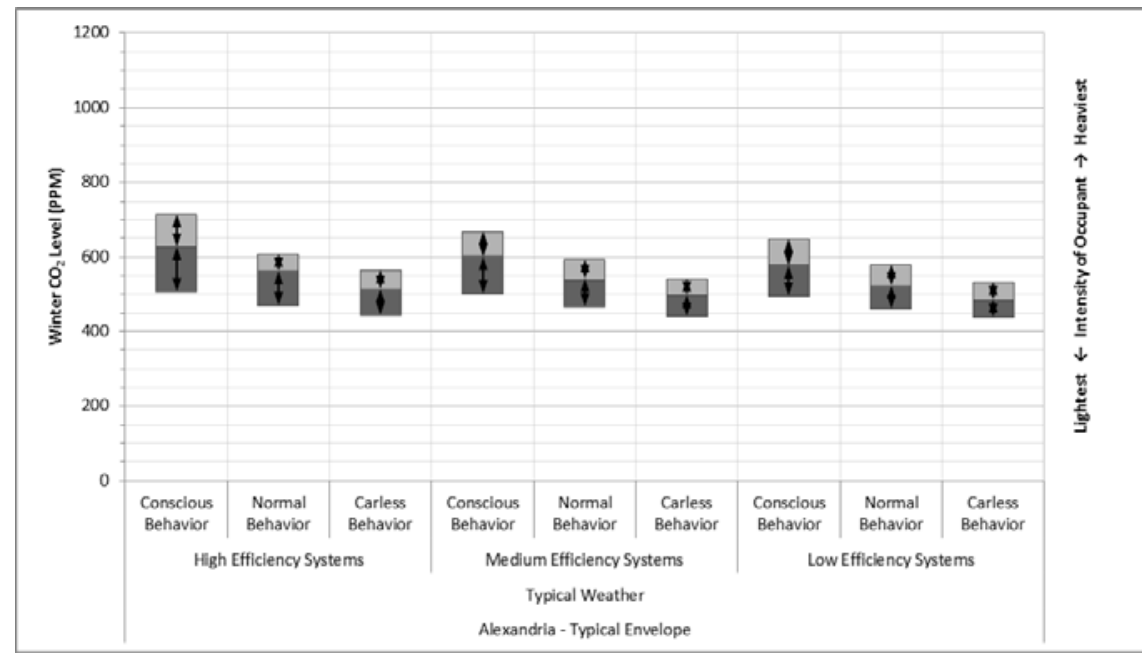

Figure 27 Winter CO2 Level for Alexandria (Typical Construction, Typical Weather) 


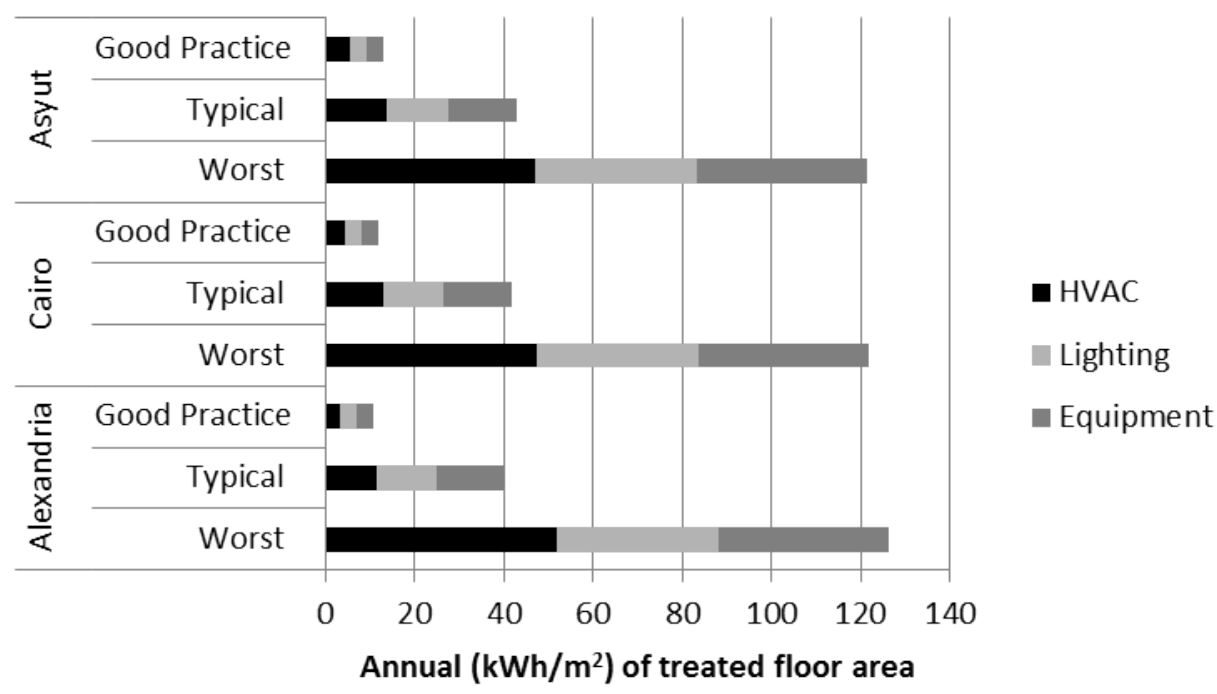

Figure 28 Energy use indices (EUIs) for best, typical, and worst combinations for the three locations office type 2

Table 9 Average energy consumption for typical type 2 office located in north coast region (Alexandria)

\begin{tabular}{|c|c|c|c|c|c|c|c|c|c|}
\hline \multicolumn{10}{|c|}{ Category Classification Based on Installed System (Equipment, Light, Cooling System) } \\
\hline Installed system efficiencies & \multicolumn{3}{|c|}{ High efficiency } & \multicolumn{3}{|c|}{ Medium efficiency } & \multicolumn{3}{|c|}{ Low efficiency } \\
\hline \multicolumn{10}{|c|}{ Energy Consumption (range) (kWh/m² p.a) } \\
\hline \multicolumn{10}{|l|}{ Typical behaviour } \\
\hline Typical Energy Consumption & \multicolumn{3}{|c|}{27.2} & \multicolumn{3}{|c|}{40.4} & \multicolumn{3}{|c|}{58.4} \\
\hline Weather Variation [Coldest / Hottest] & 25.8 & - & 29.3 & 38.7 & - & 42.8 & 52.0 & - & 56.9 \\
\hline Intensity of Occupancy [Light / Heavy] & 15.7 & - & 45.1 & 22.1 & - & 63.9 & 29.7 & - & 88.4 \\
\hline Weather + Intensity of Occupancy [Light+Cold / Heavy+Hot] & 14.7 & - & 48.9 & 21.1 & - & 67.6 & 28.3 & - & 93.1 \\
\hline \multicolumn{10}{|l|}{ Energy careless behaviour } \\
\hline Typical Energy Consumption & \multicolumn{3}{|c|}{40.6} & \multicolumn{3}{|c|}{58.1} & \multicolumn{3}{|c|}{76.5} \\
\hline Weather Variation [Coldest / Hottest] & 38.1 & - & 44.6 & 54.9 & - & 62.3 & 72.5 & - & 81.3 \\
\hline Intensity of Occupancy [Light / Heavy] & 24.5 & - & 68.4 & 36.3 & - & 92.2 & 43.8 & - & 126.2 \\
\hline Weather + Intensity of Occupancy [Light+Cold / Heavy+Hot] & 22.9 & - & 75.2 & 34.0 & - & 98.8 & 41.3 & - & 134.4 \\
\hline \multicolumn{10}{|l|}{ Energy conscious behaviour } \\
\hline Typical Energy Consumption & \multicolumn{3}{|c|}{19.3} & \multicolumn{3}{|c|}{29.3} & \multicolumn{3}{|c|}{39.7} \\
\hline Weather Variation [Coldest / Hottest] & 18.5 & - & 21 & 28.3 & - & 31.3 & 38.5 & - & 41.9 \\
\hline Intensity of Occupancy [Light / Heavy] & 10.7 & - & 31.6 & 15.6 & - & 46.2 & 21.1 & - & 64.2 \\
\hline Weather + Intensity of Occupancy [Light+Cold / Heavy & 10.2 & - & 23.8 & 15.1 & - & 49.4 & 20.4 & - & 68.3 \\
\hline
\end{tabular}




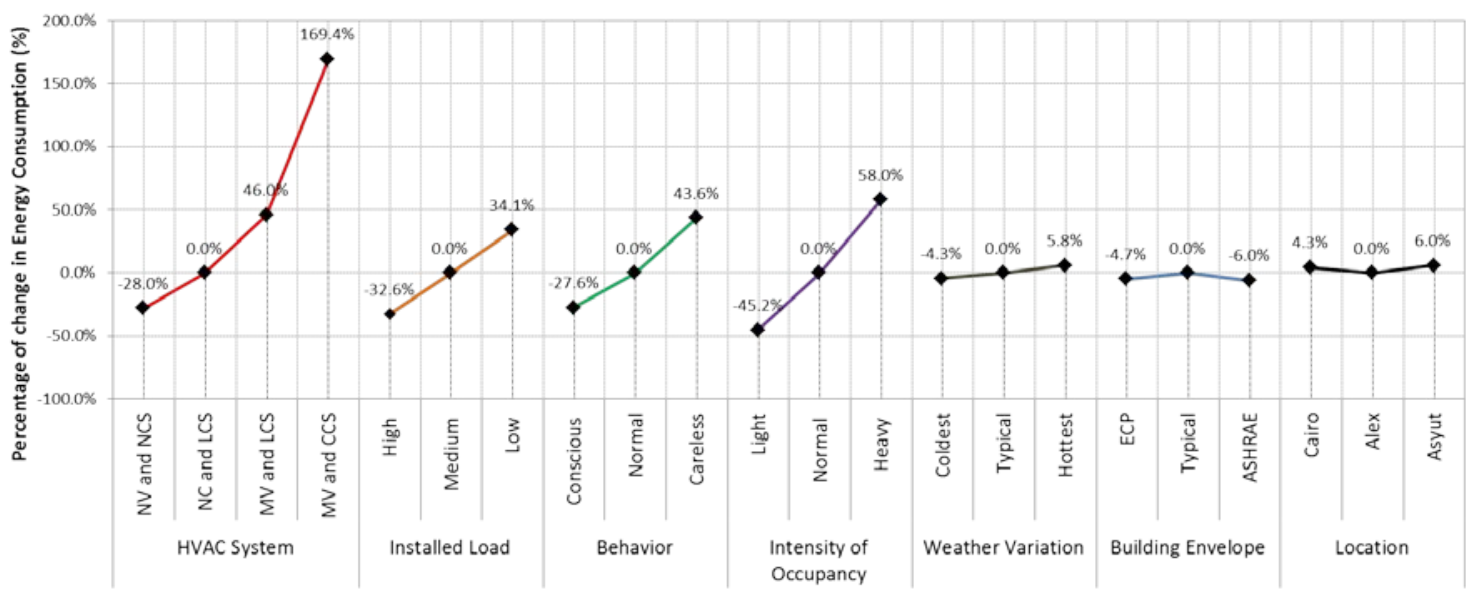

Figure 29 Combinatorial Parametric Analysis for Egyptian offices referenced to typical type 2 office in North Coast Region (Alexandria)

In Figure 29 conditions represented by the $0 \%$ values is the base model i.e. the typical type 2 office with medium efficiency installed system loads, typical behaviour and weather, typical building envelope and Alexandria location.

The results showed that the HVAC system has the biggest effect on the Energy consumption, consistent with the 59 building survey results and elsewhere. In general, the lack of central systems and provision of local personally controlled systems which are used on an as needed basis appears to result in lower energy use, centrally implemented systems which continuously condition the whole space appear to be associated with accordingly higher energy use, possibly not a surprising result but one possibly at odds with the current trajectory. The trade off with indoor environment will be discussed further later.

Other variables which have large effects are intensity of occupancy ( $+58 \%$ to $-45 \%)$, user behaviour ( $+44 \%$ to $28 \%$ ), and efficiencies of the installed loads ( $+34 \%$ to $-33 \%)$. The intensity of operations is representative of the activities carried out in the office and higher energy use with higher intensity of use is not necessarily a bad thing, rather the energy use per person hour of activity could be a better measure of effectiveness in energy use when considering different uses of an office space, it is important to understand this effect and not reward apparent low energy use due to space being underutilised [82]. The 'behaviour' and 'efficiency of installed systems' may be categories which can be influenced by policy measures, we will discuss later.

Both Location and weather effects were seen to be of the order of $6 \%$ and, perhaps surprisingly given the focus elsewhere, the effect of building envelope was of a similar order with around 6\% of variation. These small building envelope variations in the Egyptian climate are consistent with the findings from the initial parameter influence screening carried out in the earlier model calibration process where only glazing g-value and shading had significant effect (Figure 11), it should be noted that this result was for a typical building which already has some roof insulation so roof insulation should not be ignored.

These findings were consistent across different base cases, the next step then is to discuss how these findings and the modelling framework can be used to inform future policy direction.

\section{Policy directions for existing type 2 offices?}

The most prevalent type 2 office type was used as the base for the parametric analysis represented in Figure 29 and Table 9. The feasible changes that could most effectively reduce energy use are system efficiencies and behaviour changes.

By referring to Table 9 it is apparent that the typical type 2 office in Alexandria has annual electrical demand of $40.4 \mathrm{kWh} / \mathrm{m}^{2}$, this demand could be reduced to $29.3 \mathrm{kWh} / \mathrm{m}^{2}$ (27\% reduction) if the energy conscious behaviour were adopted, alternatively the demand would be reduced to $27.2 \mathrm{kWh} / \mathrm{m}^{2}$ (33\% reduction) if the high efficiency systems were installed, these two measures combined would reduce the electricity demand of the typical office to $19.3 \mathrm{kWh} / \mathrm{m}^{2}$ (52\% reduction). 
Table 9also serves to illustrate how intensity of occupancy can have a confounding effect e.g. if a building were retrofitted with high efficiency systems and occupants changed behaviour to energy conscious then a 52\% reduction in electricity demand would be expected, but if after the refit the building intensity of occupancy was increased from 'typical' to 'heavy' then the reduction in electricity demand would be only $22 \%(31.6 \mathrm{kWh} / \mathrm{m} 2)$. This highlights the requirement for a representation of intensity of occupancy within performance assessment methods.

\subsection{Improved system efficiencies.}

Several scenarios for installed system efficiencies worth exploring are elaborated in Table 10. The Egyptian Code (ECP) [6] covers lighting and cooling systems but does not cover IT and other office equipment. The ECP requires better performance than the low efficiency case (Table 4, Table 6) but is less stringent than the typical case. ASHRAE [5] specify only lighting, and cooling system efficiencies however in the scenario outlined in table 6-1 it is assumed that high efficiency IT and other office equipment would also be specified. A further 'High Efficiency' scenario has the high efficiency of the parametric study, here the increased lighting efficiency compared to ASHRAE could represent either increased system efficiency or reduced illuminance.

The performance of these three possible standards compared to a type 2 office is shown in Figure 30 . The minimum standards required in the ECP would give 18\% increase over the typical office (but $14 \%$ better than the low efficiency case). The reductions in energy use compared to the 'typical' current type 2 office for ASHRAE and High Efficiency would be $22 \%$ and 33\% respectively.

\subsection{Occupant behavior.}

A large driver for energy use is the desire for thermal satisfaction through the use of the available controls (cooling systems, windows, fans). The energy conscious behaviour which reduces electricity demand may compromise thermal comfort to some extent as illustrated in Figure 24 and Figure 25, it is worth exploring this further. Interrelationships between factors influencing thermal comfort have been captured by Paliaga and others [83],[84]. Reducing clothing levels from 1 Clo to 0.5 Clo can increase the operative temperature threshold for $\mathrm{PMV}+0.5$ from $24.8^{\circ} \mathrm{C}$ to $27.6^{\circ} \mathrm{C}$, a similar change in thermal comfort threshold can be achieved by increasing local airspeed from 0.15 to $0.8 \mathrm{~m} / \mathrm{s}$ for example by the use of fans [83], Clothing flexibility and local airspeed can therefore be adaptations allowing the temperature settings for cooling systems to be increased and hence energy demands for cooling reduced. There have been successful initiatives using these effects e.g. Coolbiz in Japan [52].

Table 10 Installed Systems Efficiency Categories

\begin{tabular}{c|c|c|c} 
High Efficiency & ASHRAE & ECP & Typical \\
\hline $\begin{array}{c}\text { Equipment }\left(8.9 \mathrm{~W} / \mathrm{m}^{2}\right) \\
\text { Lighting }\left(6 \mathrm{~W} / \mathrm{m}^{2}\right) \\
\text { SEER }(4 \mathrm{~W} / \mathrm{W})\end{array}$ & $\begin{array}{c}\text { Equipment }\left(8.9 \mathrm{~W} / \mathrm{m}^{2}\right) \\
\text { Lighting }\left(8.8 \mathrm{~W} / \mathrm{m}^{2}\right)\end{array}$ & $\begin{array}{c}\text { Equipment }\left(14.8 \mathrm{~W} / \mathrm{m}^{2}\right) \\
\text { Lighting }\left(14 \mathrm{~W} / \mathrm{m}^{2}\right)\end{array}$ & $\begin{array}{c}\text { Equipment }\left(14.8 \mathrm{~W} / \mathrm{m}^{2}\right) \\
\text { SEER }(3.8 \mathrm{~W} / \mathrm{W})\end{array}$ \\
\hline SEER $(3 \mathrm{~W} / \mathrm{W})$ & SEER $(3.5 \mathrm{~W} / \mathrm{W})$ \\
\hline Cooling use $(0.45)$ & Cooling use $(0.45)$ & Cooling use $(0.45)$ & Cooling use $(0.45)$ \\
\hline SEEReff $(9 \mathrm{~W} / \mathrm{W})$ & SEEReff $(8.5 \mathrm{~W} / \mathrm{W})$ & SEEReff $(7 \mathrm{~W} / \mathrm{W})$ & SEEReff $(8 \mathrm{~W} / \mathrm{W})$
\end{tabular}




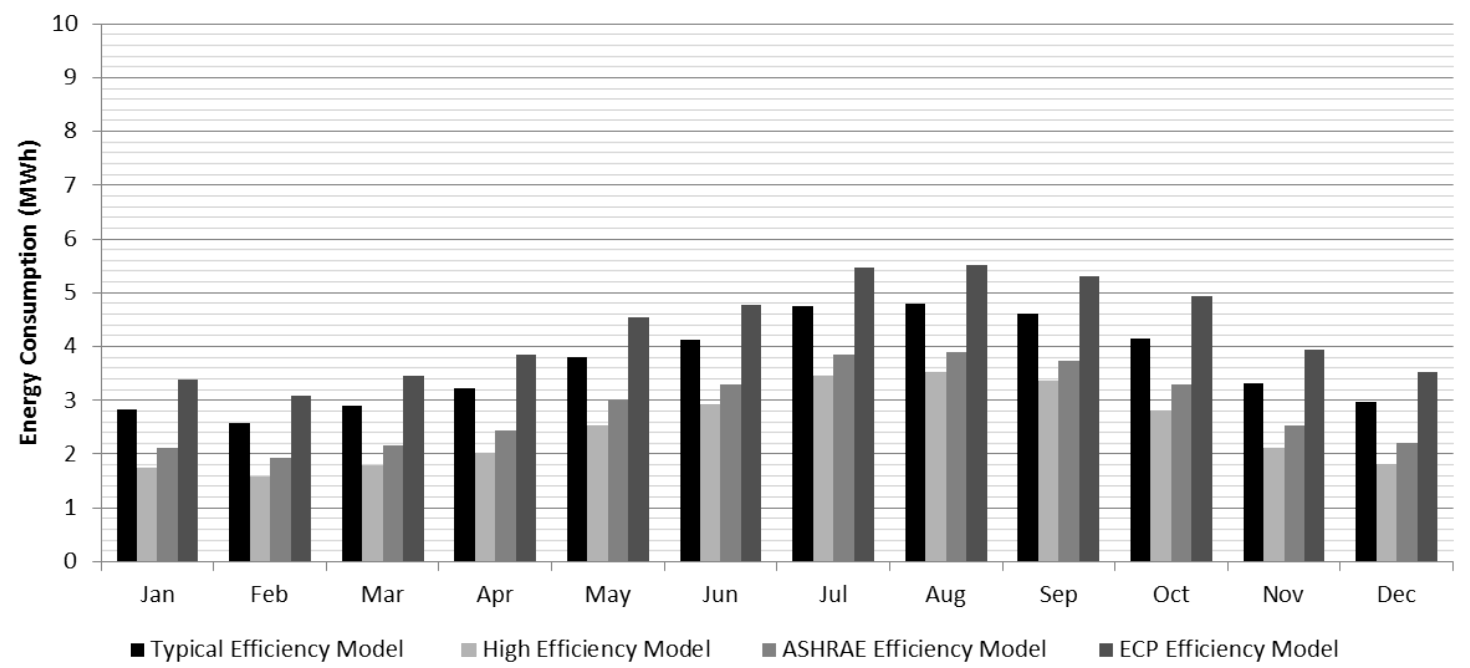

Figure 30 Energy consumption for typical type 2 office for various equipment efficiency scenarios

Energy use is significantly reduced (27\% for the typical office, Figure 31 ) if energy conscious behaviour is adopted, including a cooling set point temperature of $25^{\circ} \mathrm{C}$, without adaptations, this however leads to thermal dissatisfaction levels beyond those experienced in the typical office (Figure 32). If adaption is allowed through reducing summer clothing levels from 0.7 to 0.5 Clo during June to October and from 1.0 to 0.7 Clo in May \& November then PPD could be maintained in an acceptable range (Figure 32).

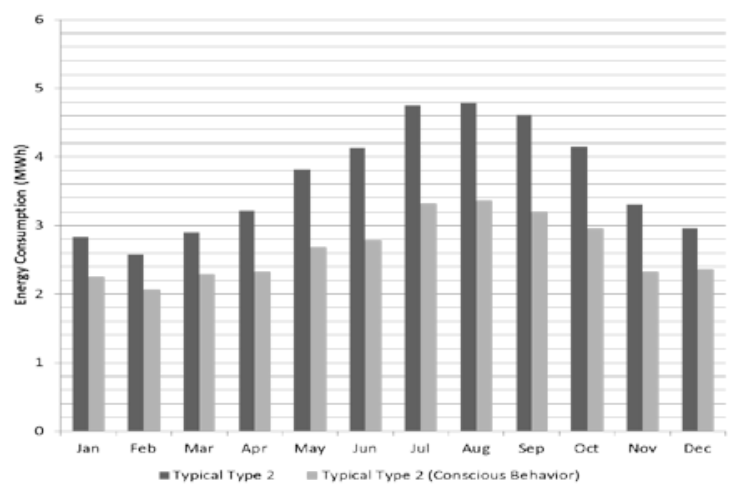

Figure 31 Electricity consumption for typical type 2 office with typical and energy conscious behavior.

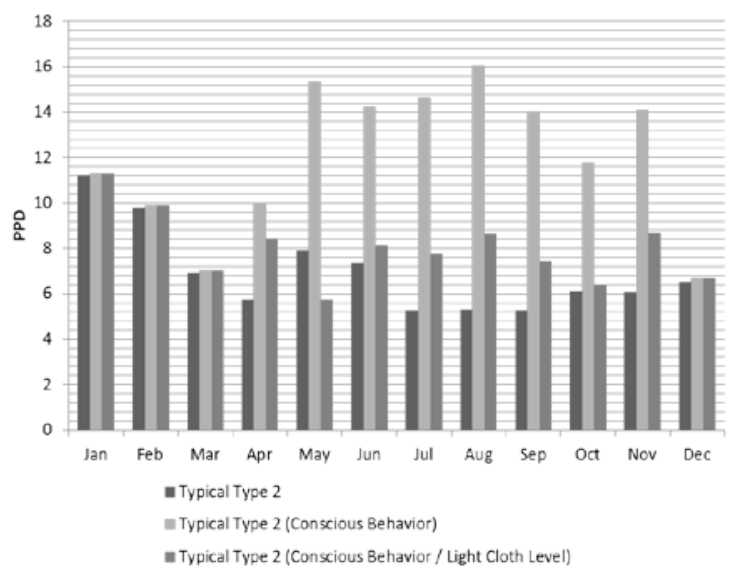

Figure 32 PPD for typical type 2 office with different behavior and clothing levels.

It is possible to envisage a further reduction in energy use through a raising the cooling set point to $27^{\circ} \mathrm{C}$ and use of a ceiling fan to increase air velocity in addition to the clothing adaptation. An air velocity of $0.5 \mathrm{~m} / \mathrm{s}$ instead of $0.15 \mathrm{~m} / \mathrm{s}$ by user controlled ceiling fans was found to give both improved energy performance (Figure 33) and acceptable comfort (Figure 34) (assuming one 55W fan covering a $90 \mathrm{~m}^{2}$ floor area). The annual electricity demand for the $27^{\circ} \mathrm{C}$ cooling set point with ceiling fans scenario is reduced by $33 \%$ from the typical office case, compared to the $27 \%$ reduction for the $25^{\circ} \mathrm{C}$ set point no fans case. 


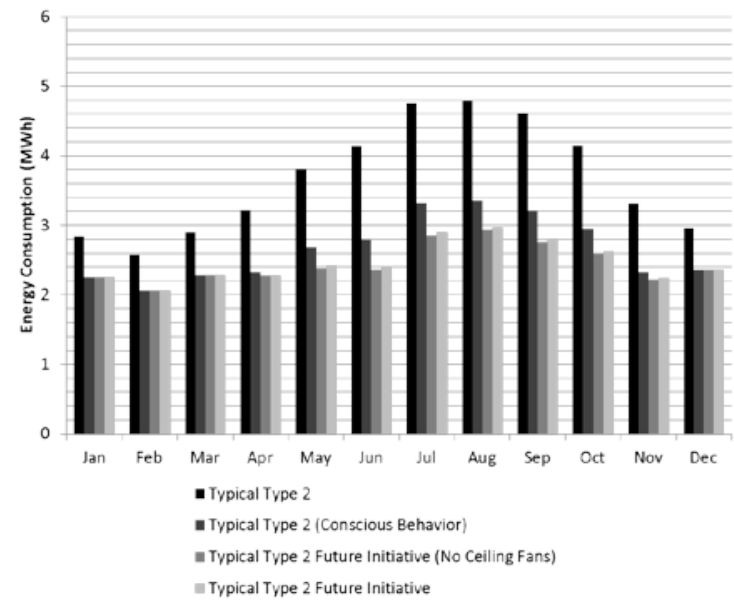

Figure 33 Monthly electricity consumption for typical type 2 office with typical, energy conscious, and $27^{\circ} \mathrm{C}$ plus fans behaviours.

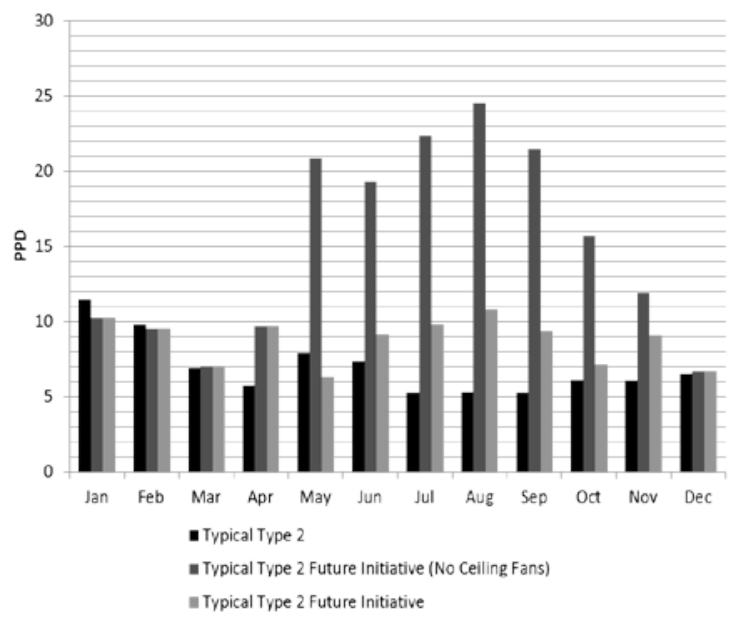

Figure 34 PPD for typical type 2 office with typical, energy conscious, and 27oC plus fans behaviours.

\section{Discussion}

The overall aim of the work presented here was to explore the energy and indoor environmental performance of Egyptian offices and provide insights that can begin to usefully inform future strategy for this sector.

This paper elaborates the steps taken in this exploration: the 59 office energy survey, the single building energy and environmental monitoring, the creation of a representative modelling framework, and the use of that framework to provide further insights beyond the survey and monitoring.

The survey highlighted that energy use is higher in more fully serviced buildings, a similar finding to that reported elsewhere [34, 35]. The provision of centrally controlled comfort cooling and ventilation across the entire indoor space continuously throughout the occupied period has an associated energy penalty in contrast to the situation where individuals have control and only occupied workspaces are conditioned as required.

On the opposite side of this argument against continuously running centralised systems is the potential highlighted in the analysis for indoor environmental conditions to be compromised by energy conscious behaviour e.g. through lower ventilation rates and associated increases in $\mathrm{CO}_{2}$ (and possibly other pollutants). This is a conflict inherent in the use of natural ventilation[85, 86]. The provision of desktop $\mathrm{CO}_{2}$ monitors and guidance to occupants of naturally ventilated buildings is being mandated in some countries as a means of ensuring appropriate setting of ventilation openings [87] addressing this concern. In office environments the use of ventilation to eliminate odours may be sufficient unless there are unusual sources of pollutants dangerous to health. A further potential issue with natural ventilation can be that there is no filtration of the outdoor air which could be problematic depending on the specifics of the location; outdoor air quality is another area which may become an increasing focus in policy.

The type 2 naturally ventilated and locally cooled office buildings are common, if these were to be converted or replaced by fully serviced buildings then it would appear that this would greatly increase the overall energy demand of the office sector (more than 2x). Widespread adoption of 'advanced' building standards from elsewhere should be carefully evaluated against existing actual energy use rather than the reference building approach commonly used in those standards[38],[39].

To reduce the energy demand of existing type 2 (and other existing offices) the work presented here suggests that the most effective strategies would be to influence (i) the efficiency of the installed loads and (ii) the occupant behaviour in terms of adaption, and efficient use of energy using systems including local cooling. Many other countries have used awareness campaigns, passed legislation and provided incentives to encourage adoption of high efficiency systems including IT equipment, cooling systems, lighting etc. Similarly there have 
been successful initiatives to encourage more energy efficient behaviour and to recognise which could be reviewed and potentially adapted to the Egyptian context.

The influence of building fabric improvements on existing type 2 offices, apart from window shading / solar transmittance and possibly roof insulation, was seen to be relatively small at up to $8 \%$. For fully serviced offices however these factors may have a greater impact.

The work presented here is intended to provide useful insights and make a contribution; this work is intended to sit alongside the work of others and be further extended in future in order to give a sound basis for future policy. The 59 office survey and case study in Alexandria was based on the set of buildings available, the sample is small and while these appear to be representative of common office types across Egypt more data collection should be done to confirm this. The datasets created in this work are only a start, it is important that further studies are conducted across larger samples and different contexts to allow a more comprehensive understanding.

Monitoring must also be used on an ongoing basis to allow actual building performance to be understood and provide feedback for the buildings sector, experience elsewhere has highlighted that policy does not always result in the intended results and that monitoring and reporting of actual performance is key if performance gaps are to be avoided [36, 37].

While the methods developed and elaborated here have been applied to the Egyptian office context, they are intended to be more generally applicable to other situations and building types.

\section{Conclusion}

Insights into the current performance of Egyptian office buildings is provided through a 59 building energy survey plus investigation of a case study of the most commonly found type which has natural ventilation and local cooling systems.

Office buildings were categorized into 4 types by servicing strategy: natural ventilation with no cooling, natural ventilation with local cooling, mechanical ventilation with local cooling, centrally serviced mechanical ventilation and cooling and energy use benchmarks provided.

A process to represent observed performance in a representative model and appropriate input parameter sets is presented. The model was then used to investigate the impacts on performance of the most common type of office for a range of parameters including: location, weather, building envelope, intensity of occupancy, behaviour, and installed systems including HVAC strategy.

HVAC strategy was identified as the most significant factor, current Egyptian offices with natural ventilation and local cooling under personal control have less than $50 \%$ of the electricity demand of centrally serviced buildings where the space is fully conditioned throughout the occupation period. Installed system efficiencies (HVAC, lights, equipment) and occupant behaviours (e.g. use of systems, cooling set points) were also identified as having a potential for energy saving of around $30 \%$ each or $50 \%$ in combination for these typical offices.

Possible policy measures to promote (i) energy efficient systems, and (ii) energy conscious behaviour, are proposed and discussed, including potential trade-offs between energy conscious behaviour and indoor environmental quality.

\section{References}

1. Eberhard, A., et al., Underpowered: the state of the power sector in Sub-Saharan Africa. Background paper, 2008.6.

2. Zhou, Y., et al., Modeling the effect of climate change on US state-level buildings energy demands in an integrated assessment framework. Applied Energy, 2014. 113: p. 1077-1088. 
3. ECP306/1-2005, The Egyptian Residential Buildings Energy Code. Housing and Building National Research Center, HBRC 2005 Egypt.

4. Raslan, R.M.S., Performance based regulations: the viability of the modelling approach as a methodology for building energy compliance demonstration. 2010, UCL (University College London).

5. Standard, A., 90.1-2013 'Energy Standard for Buildings Except Low-Rise Residential Buildings'. 2013.

6. ECP306/2-2005, The Egyptian Commercial Buildings Energy Code. Housing and Building National Research Center, HBRC 2005 Egypt.

7. Council, U.G.B., LEED: Leadership in energy and environmental design. 2011.

8. system, E.G.B.C.T.G.P.r., Egyptian Green Building Council The GREEN PYRAMID rating system. 2009, Egypt.

9. Clarke, J.A., Energy simulation in building design. 2001: Routledge.

10. Reddy, T.A. and K.K. Andersen, An evaluation of classical steady-state off-line linear parameter estimation methods applied to chiller performance data. HVAC\&R Research, 2002. 8(1): p. 101-124.

11. Zhao, H.-x. and F. Magoulès, A review on the prediction of building energy consumption. Renewable and Sustainable Energy Reviews, 2012. 16(6): p. 3586-3592.

12. Attia, S., A tool for design decision making: zero energy residential buildings in hot humid climates. Vol. 4. 2012: Presses univ. de Louvain.

13. Swan, L.G. and V.I. Ugursal, Modeling of end-use energy consumption in the residential sector: A review of modeling techniques. Renewable and sustainable energy reviews, 2009. 13(8): p. 1819-1835.

14. Kavgic, M., et al., A review of bottom-up building stock models for energy consumption in the residential sector. Building and environment, 2010. 45(7): p. 1683-1697.

15. Mauro, G.M., et al., A new methodology for investigating the cost-optimality of energy retrofitting a building category. Energy and Buildings, 2015. 107: p. 456-478.

16. Ascione, F., et al., A Methodology to Assess and Improve the Impact of Public Energy Policies for Retrofitting the Building Stock: Application to Italian Office Buildings. International Journal of Heat and Technology, 2016. 34: p. S277-S286.

17. Crawley, D.B., Building Performance Simulation: A Tool For Policymaker, in Mechanical And Aerospace Engineering. 2008, Strathclyde University.

18. Coakley, D., P. Raftery, and M. Keane, A review of methods to match building energy simulation models to measured data. Renewable and Sustainable Energy Reviews, 2014. 37: p. 123-141.

19. Recast, E., Directive 2010/31/EU of the European Parliament and of the Council of 19 May 2010 on the energy performance of buildings (recast). Official Journal of the European Union, 2010. 18(06): p. 2010.

20. Baldwin, R., et al., BREEAM 98 for Offices. Building Research Establishment, Watfordt, 1998.

21. Crawley, D.B., et al., Contrasting the capabilities of building energy performance simulation programs. Building and environment, 2008. 43(4): p. 661-673. 
22. Attia, S., et al., Selection criteria for building performance simulation tools: contrasting architects' and engineers' needs. Journal of Building Performance Simulation, 2012. 5(3): p. 155-169.

23. IES-VE, Virtual Environment (VE) by Integrated Environmental Solutions (IES). 2014.

24. Fabrizio, E. and V. Monetti, Methodologies and advancements in the calibration of building energy models. Energies, 2015. 8(4): p. 2548-2574.

25. Reddy, T.A., I. Maor, and C. Panjapornpon, Calibrating detailed building energy simulation programs with measured data-Part I: General methodology (RP-1051). Hvac\&R Research, 2007. 13(2): p. 221-241.

26. Guideline, A., Guideline 14-2002, Measurement of Energy and Demand Savings. American Society of Heating, Ventilating, and Air Conditioning Engineers, Atlanta, Georgia, 2002.

27. Coakley, D., et al. Calibration of a detailed BES model to measured data using an evidencebased analytical optimisation approach. in Proceedings of the 12th International IBPSA Conference. Sydney, Australia. 2011.

28. Raftery, P., M. Keane, and A. Costa, Calibrating whole building energy models: Detailed case study using hourly measured data. Energy and Buildings, 2011. 43(12): p. 3666-3679.

29. Elharidi, A.M., et al., Calibration Of Numerical Simulations Modeling Of Nonresidential Building In Hot Humid Climate Region. 2015.

30. Cooper, I., Post-occupancy evaluation-where are you? Building Research \& Information, 2001. 29(2): p. 158-163.

31. Energy, A., Energy consumption guide 19: energy use in offices, in Energy. 2003.

32. EIA, U., International energy outlook 2013, in US Energy Information Administration (EIA). 2013: USA.

33. NCM, National Calculation Methodology (NCM) Modeling Guide (for buildings other than dwellings in England and Wales), Building Research Establishment Ltd, 2011., in 20th November 2015: Release of iSBEM_v5.2.g. 2011.

34. Abd-Allah, N.R., et al., Energy Conservation in Existing Office Building: Case study Petrojet Company Head Office Buildings in Cairo, Egypt. 2014.

35. Ezzeldin, S.M.N., Mixed-Mode Cooling Design for Office Buildings in Arid Climates, Ph.D. Thesis. 2011, De Montfort University: De Montfort University.

36. Menezes, A.C., et al., Predicted vs. actual energy performance of non-domestic buildings: Using post-occupancy evaluation data to reduce the performance gap. Applied Energy, 2012. 97: p. 355-364.

37. De Wilde, P., The gap between predicted and measured energy performance of buildings: $A$ framework for investigation. Automation in Construction, 2014. 41: p. 40-49.

38. Tuohy, P.G. and G.B. Murphy, Are current design processes and policies delivering comfortable low carbon buildings? Architectural Science Review, 2015. 58(1): p. 39-46.

39. Tuohy, P.G. and G.B. Murphy, Closing the gap in building performance: learning from BIM benchmark industries. Architectural Science Review, 2015. 58(1): p. 47-56.

40. Attia, S.G.M., et al., Towards strategic use of BPS tools in Egypt. IBPSA, 2011. 1.

41. Attia, S., A. Evrard, and E. Gratia, Development of benchmark models for the Egyptian residential buildings sector. Applied Energy, 2012. 94: p. 270-284. 
42. Elharidi, A.M., P.G. Tuohy, and M.A. Teamah. Facing the growing problem of the electric power consumption in Egyptian residential building using building performance simulation program. in Building Simulation Cairo 2013 Conference. 2013.

43. Mahdy, M.M. and M. Nikolopoulou, Evaluation of fenestration specifications in Egypt in terms of energy consumption and long term cost-effectiveness. Energy and Buildings, 2014. 69: p. 329-343.

44. Dabaieh, M., et al., Reducing cooling demands in a hot dry climate: A simulation study for non-insulated passive cool roof thermal performance in residential buildings. Energy and Buildings, 2015. 89: p. 142-152.

45. ElDabosy, M.M. and M.M. AbdEIrahman, Evaluation of Office Spaces Ventilation using Simulation software El-Dakahlia Governmental Headquarter as a Pilot Renovation. 2013.

46. El Mohimen, M.A., G. Hanna, and M. Krarti, Analysis of daylighting benefits for office buildings in Egypt. Journal of solar energy engineering, 2005. 127(3): p. 366-370.

47. Saleem, A., et al., An Analysis of Thermal Comfort and Energy Consumption within Public Primary Schools in Egypt. 2016.

48. Sheta, W. and S. Sharples. A Building Simulation Sustainability Analysis to Assess Dwellings in a New Cairo Development. in Fourth National Conference of IBPSA-USA, New York City, New York. 2010.

49. Hanna, G.B., Energy Analysis for New Office Buildings in Egypt. 2013.

50. EN, B., 15251: 2013, in Indoor environmental input parameters for design and assessment of energy performance of buildings-addressing indoor air quality, thermal environment, lighting and acoustics. 2013.

51. Givoni, B., Climate considerations in building and urban design. 1998: John Wiley \& Sons.

52. Haneda, M., et al., A field measurement of thermal environment in COOL BIZ office and the evaluation on productivity by a questionnaire survey. Journal of Environmental Engineering, 2009. 74(637): p. 389-396.

53. Elharidi, A.M., et al., Energy and indoor environmental performance of typical Egyptian offices: Survey, baseline model and uncertainties. Energy \& Buildings, 2017. 135: p. 367-384.

54. Attia, S., A tool for design decision making: zero energy residential buildings in hot humid climates, Ph.D. Thesis. 2012, Presses univ. de Louvain.

55. Westphal, F.S. and R. Lamberts. Building simulation calibration using sensitivity analysis. in Ninth International IBPSA Conference. 2005. Citeseer.

56. Ashrae, A., Standard 55-2004, Thermal environmental conditions for human occupancy. American Society of Heating, Refrigerating and Air-Conditioning Engineering, Atlanta, GA, 2004.

57. Nicol, F. and M. Humphreys, Derivation of the adaptive equations for thermal comfort in free-running buildings in European standard EN15251. Building and Environment, 2010. 45(1): p. 11-17.

58. Taleghani, M., et al., A review into thermal comfort in buildings. Renewable and Sustainable Energy Reviews, 2013. 26: p. 201-215.

59. de Dear, R.J. and G.S. Brager, Thermal comfort in naturally ventilated buildings: revisions to ASHRAE Standard 55. Energy and buildings, 2002. 34(6): p. 549-561. 
60. Robaa, S., Evaluation of sunshine duration from cloud data in Egypt. Energy, 2008. 33(5): p. 785-795.

61. https://energyplus.net/weatherlocation/africa_wmo_region_1/EGY//EGY_Alexandria.623180_ETMY.

62. Zhang, Q., J. Huang, and S. Lang, Development of typical year weather data for Chinese locations/Discussion. ASHRAE transactions, 2002. 108: p. 1063.

63. Fanger, P.O., Thermal comfort. Analysis and applications in environmental engineering. Thermal comfort. Analysis and applications in environmental engineering., 1970.

64. Cen, E., 15251, Indoor environmental input parameters for design and assessment of energy performance of buildings addressing indoor air quality, thermal environment, lighting and acoustics. European Committee for Standardization, Brussels, Belgium, 2007.

65. Elharidi, A.M. and P.G. Tuohy, Capturing Uncertainty in Operation, Behavior and Weather in Building Performance Assessment: An Egyptian Case Study., in 9th Windsor Conference. 2016: Cumberland Lodge, Windsor, UK.

66. Royapoor, M. and T. Roskilly, Building model calibration using energy and environmental data. Energy and Buildings, 2015. 94: p. 109-120.

67. Heo, Y., R. Choudhary, and G. Augenbroe, Calibration of building energy models for retrofit analysis under uncertainty. Energy and Buildings, 2012. 47: p. 550-560.

68. Iqbal, I. and M.S. Al-Homoud, Parametric analysis of alternative energy conservation measures in an office building in hot and humid climate. Building and environment, 2007. 42(5): p. 2166-2177.

69. Fahmy, M., M.M. Mahdy, and M. Nikolopoulou, Prediction of future energy consumption reduction using GRC envelope optimization for residential buildings in Egypt. Energy and Buildings, 2014. 70: p. 186-193.

70. Dorm, M. and R. Amor, The creation of weather data files to fulfil the simulation needs of New Zealand. 1993.

71. Hui, S.C. and K. Cheung. Multi-year (MY) building simulation: is it useful and practical. in Proc. of the IBPSA Building Simulation'97 Conference. 1997.

72. Crawley, D.B., J.W. Hand, and L.K. Lawrie. Improving the weather information available to simulation programs. in Proceedings of Building Simulation'99. 1999. Citeseer.

73. Kershaw, T., M. Eames, and D. Coley, Comparison of multi-year and reference year building simulations. Building Services Engineering Research and Technology, 2010. 31(4): p. 357-369.

74. Narowski, P., M. Janicki, and D. Heim. Comparison of Untypical Meteorological Years (UMY) and their influence on building energy performance simulations. in Proc. of Conference "Building Simulation-BS2013", Le Bourget-du-Lac. 2013.

75. Georgiou, G., et al., A study of the effect of weighting indices for the development of TMY used for building simulation. 2013.

76. Crawley, D.B. Creating weather files for climate change and urbanization impacts analysis. in Building Simulation. 2007. IBPSA Beijing.

77. Crawley, D.B. and L.K. Lawrie, RETHINKING THE TMY: IS THE 'TYPICAL'METEOROLOGICAL YEAR BEST FOR BUILDING PERFORMANCE SIMULATION? 
78. Ali, A.A.E.-M.M., Using simulation for studying the influence of vertical shading devices on the thermal performance of residential buildings (Case study: New Assiut City). Ain Shams Engineering Journal, 2012. 3(2): p. 163-174.

79. Corrado, V., H.E. Mechri, and E. Fabrizio. Building energy performance assessment through simplified models: application of the ISO 13790 quasi-steady state method. in Proceedings of building simulation. 2007.

80. Karjalainen, S., Should we design buildings that are less sensitive to occupant behaviour? A simulation study of effects of behaviour and design on office energy consumption. Energy Efficiency, 2016: p. 1-14.

81. Tuohy, P.G., et al., Comfort driven adaptive window opening behaviour and the influence of building design. 2007.

82. Morton, E.M. and P.G. Tuohy. Embracing variations in patterns of use, pre and post design phase, to improve tenant energy performance. in 4th Annual CIBSE ASHRAE Technical Symposium. 2014.

83. Paliaga, G., Moving air for comfort. ASHRAE journal, 2009. 51(5): p. 18.

84. Rijal, H.B., et al. An algorithm to represent occupant use of windows and fans including situation-specific motivations and constraints. in Building Simulation. 2011. Springer.

85. Persily, A.K., Evaluating building IAQ and ventilation with indoor carbon dioxide. Transactions-American society of heating refrigerating and air conditioning engineers, 1997. 103: p. 193-204.

86. Persily, A. and W.S. Dols, The relation of $\mathrm{CO} 2$ concentration to office building ventilation, in Air change rate and airtightness in buildings. 1990, ASTM International.

87. Seppänen, O., W. Fisk, and M. Mendell, Association of ventilation rates and CO2 concentrations with health andother responses in commercial and institutional buildings. Indoor air, 1999. 9(4): p. 226-252. 